\title{
1 3D-Cardiomics: A spatial transcriptional atlas of the mammalian
}

\section{2 heart}

3

4 Monika Mohenska ${ }^{1,2,12,}$, Nathalia M. Tan ${ }^{1,2,1,12}$, Alex Tokolyi ${ }^{3,12}$, , Milena B. Furtado ${ }^{3,4}$, Mauro W. Costa ${ }^{3,4}$,

5 Andrew J. Perry ${ }^{5}$, Jessica Hatwell-Humble ${ }^{3,6}$, Karel van Duijvenboden', Hieu T. Nim ${ }^{3.8}$, Susan K.

6 Nilsson ${ }^{3,6}$, David R. Powell ${ }^{5}$, Nadia A. Rosenthal ${ }^{3,4,9}$ Fernando J. Rossello $^{* 1,2,3,11}$, Mirana Ramialison ${ }^{3,1,1,13}$, 7 and Jose M. Polo's,2,3,13

8

91 Department of Anatomy and Developmental Biology, Monash University, Wellington

10 Road, Clayton, Victoria, Australia.

112 Development and Stem Cells Program, Monash Biomedicine Discovery Institute,

12 Wellington Road, Clayton, Victoria, Australia.

133 Australian Regenerative Medicine Institute, Monash University, Wellington Road,

$14 \quad$ Clayton, Victoria, Australia

154 The Jackson Laboratory, Bar Harbor, ME, USA

165 Monash Bioinformatics Platform, Monash University, Wellington Road, Clayton,

$17 \quad$ Victoria, Australia

186 Biomedical Manufacturing, CSIRO Manufacturing, Bag 10, Clayton South, Australia

197 Department of Medical Biology, Academic Medical Centre, Amsterdam, The

$20 \quad$ Netherlands

218 Faculty of Information Technology, Monash University, Clayton, Victoria, Australia

229 National Heart and Lung Institute, Imperial College London, London, United Kingdom

$23 \quad$ Systems Biology Institute Australia, Clayton, Victoria, Australia

2411 University of Melbourne Centre for Cancer Research, University of Melbourne, Melbourne,

$25 \quad$ Victoria, Australia

$26 \quad 12$ Equal Contribution

$27 \quad 13 \quad$ Equal senior author 
$29 *$ Correspondence: mirana.ramialison@ monash.edu (M.R.)

$30 *$ *orrespondence: jose.polo@monash.edu (J.M.P.)

$31 *$ Correspondence: frossello@unimelb.edu (F.J.R)

\section{Abstract}

33 Understanding spatial gene expression and regulation is key to uncovering developmental and

34 physiological processes, during homeostasis and disease. Numerous techniques exist to gain gene 35 expression and regulation information, but very few utilise intuitive true-to-life three-dimensional 36 representations to analyze and visualize results. Here we combined spatial transcriptomics with 3D 37 modelling to represent and interrogate, transcriptome-wide, three-dimensional gene expression and 38 location in the mouse adult heart. Our study has unveiled specific subsets of genes that display 39 complex spatial expression in organ sub-compartments. Also, we created a web-based user interface 40 for spatial transcriptome analysis and visualization. The application may be accessed from http://3d-

41 cardiomics.erc.monash.edu/.

\section{Keywords}

43 Cardiac model, spatial transcriptomics, cardiac systems, bioinformatics, systems biology, 3D organ,

44 data visualization 


\section{Introduction}

52 Organs or complex systems display a precise cellular spatial organisation which, if disrupted, can lead

53

54

55

to functional changes and, eventually, disease. The mammalian heart is a complex organ composed of four structurally and functionally distinct chambers: left and right ventricles and atria (Moorman \& Christoffels 2003), connected to the circulatory system through major vessels. It is composed of different cellular layers including cells types such as cardiomyocytes, fibroblasts, endothelial and immune cells (Massaia et al. 2018). This complex architecture ensures a plethora of functions such as contraction, electrical current conduction, blood and lymph circulation, and immune response. Different regions and structures of the heart exert different functions, hence molecular and physiological properties vary within the heart. For instance, intracardiac pressure is the highest within the left ventricle, which has the thickest muscular wall in the heart, to ensure blood distribution in the body. In contrast, the right atrium displays thin wall chambers as it only pumps blood to the lungs. Any anatomical or physiological alterations to these sub-compartments will impair cardiac function. For example, Hypoplastic Left Heart (Siffel et al. 2015), characterised by an atrophic or absent left ventricle, or transposition of the Great Arteries (Garne et al. 2007), manifested by an inversion of the connection of the pulmonary artery and aorta to the heart, are severe forms of cardiac malformations that require invasive surgery in the first years of life and can lead to death.

Our understanding of which genes are responsible for the formation and maintenance of specific cardiac sub-compartments is still limited. Thus knowledge of structure-specific gene expression is key if we want to address this. The importance of spatio-temporal gene expression and regulation in the heart has been well appreciated for decades (Waardenberg et al. 2014). Techniques such as is in situ hybridization or immunohistochemistry have shed light on the function of several genes in specific structures of the heart. However, this can only be done in a biased way and one or two genes at a time. In the last few years, different technologies to resolve spatial genome-wide expression in a systematic manner in whole organs or organism have emerged. For instance, spatial transcriptomics allows to interrogate gene wide expression in histological sections (Ståhl et al. 2016) (Asp et al. 2017) (X. Wang et al. 2018) as well as Slide-seq (Rodriques et al. 2019) and spatially barcoded arrays (Asp 
et al. 2017). DVEX (Karaiskos et al. 2017), Tomo-seq (Junker et al. 2014) and Geo-seq (Chen et al.

2017) have also been developed to capture different degrees of spatial resolution of gene expression in three dimensions. Recently, Burkhard and Bakkers utilised Tomo-seq to map the spatial transcriptome of the embryonic heart (Burkhard \& Bakkers 2018). Although these techniques have enhanced our ability to determine and explore the spatial transcriptome of some model organisms and tissues, they have mostly been restricted to the size of the studied tissue, organ or organism. Consequently, to date, none of these methods have systematically investigated gene expression in 3D in adult mammalian hearts.

Here we present 3D-cardiomics, a three-dimensional gene expression atlas of the murine adult heart generated from RNA-sequencing of 18 anatomical sections. Analysis of this dataset revealed regional synexpression groups, including known cardiac-markers and novel compartment-specific genes. In addition, we present a novel visualization interface that facilitates interactive gene expression navigation, synexpression analysis and differential gene expression across sections. Our study provides a unique framework to explore gene expression in an adult mouse heart where information is scarce, and enables the identification of spatially-restricted genes at an unprecedented resolution.

\section{Revealing the spatial transcriptional profile of the murine adult heart}

97 We aimed to evaluate the spatial transcriptional profile of the adult mouse heart. To achieve this, mouse hearts were isolated and microdissected in 18 anatomical sections. Microdissection of the heart consisted first in splitting the major vessels, atria and ventricles (Figure 1A). Three equally spaced

100 transverse dissections were then performed on the ventricle, followed by further longitudinal

101 dissections of the ventricles. High-throughput whole transcriptome sequencing (RNA-seq) was

102 performed in duplicates for each of the 18 sections. Replicates highly correlate (Figure S1A) 
103 following batch effect removal (Figures S1B,C). In parallel, a 3D in silico model of the mouse heart

104 (de Boer et al. 2011), (Aanhaanen et al. 2010) was digitally partitioned (Figure 1B) mimicking the 18

105 sections of the microdissected hearts (Figure 1C). RNA-sequencing data from each anatomical section

106 was then mapped to its respective 3D partition. The software package Unity [https://unity.com/] was

107 chosen to build the 3D-cardiomics tool due to its capabilities in operating 3D models. RNA

108 expression values of the 18 pieces for each gene were mapped as colours on to the 18 virtual heart

109 pieces previously dissected in silico. This allowed us to generate a digital transcriptome map of the

110 composing sections of the adult mouse heart, explorable in three-dimensions, which we used to

111 investigate spatial transcriptional networks within the heart.

113 Unravelling the structural transcriptome of the adult mouse heart

114 To gain insight into the spatial distribution of gene expression in the adult mouse heart, we examined

115 how distinct cardiac sections clustered in low dimensional space. Correspondence analysis (CoA)

116 revealed that the atria and major vessels diverged from the ventricular sections in the first two

117 components (Figure 2A). The top 500 most variable genes of the first two components of the CoA

118 explained most of the variability found between the cardiac sections and were associated with higher

119 expression in either the atria or major vessels (Figure 2A). Investigation of variance explained by all

120 components of the CoA revealed that most of the variability (62\%) was explained by the first

121 component if all sections were included in the analysis (Figure S2A). In contrast, the first component

122 contributes only to $26 \%$ of the variance when only ventricular sections were analyzed (Figure S2B).

123 To further explore the differences between the superior and inferior sections of the heart, we

124 performed differential gene expression (DGE) analysis across the 18 sections, which confirmed the

125 clustering of atrial and great vessel sections separately from the ventricular sections (Figure 2B). This

126 is in accordance with the divergence observed from the CoA (Figure 2A). In order to spatially

127 visualize the molecular segregation highlighted by the CoA and the DGE analysis, representative

128 genes of each quadrant (Figure 2A) and cluster (Figure 2B) were visualized on our 3D in silico model 
129 (Figure 2C). The visualizations confirmed that the spatial spread of genes correlated with the spatial

130 spread of sections in the first two dimensions of the CoA. A gradient across the second dimension was

131 present which had separated the vessels from the atria. For instance, unbiasedly identified, Tat and

$132 U t s 2 b$ were highly expressed in the atria; Bmp3 and Gata5 have variable expression between the atria;

133 Adipoq and Ponl are highly expressed in the major vessels. A noticeable gradient throughout the first

134 dimension of the CoA, showed that the ventricles segregated from the superior tissues of the heart.

135 The genes characterising the ventricles include Irxl and Myl3 (Figure 2C). Some of these genes have

136 been previously characterised in the specified sub-compartments, whilst others are novel candidate

137 markers (Motoki et al. 2009) (Yue et al. 2017) (Gu et al. 2012), (Tward et al. 2002), (Shih et al.

138 1998), (Patel et al. 2008), (Andersen et al. 2012), (Zhi et al. 2016). Altogether, these findings

139 confirmed that major spatial gene expression differences in the heart correlate with chamber identity.

141 To uncover global synexpression groups beyond these representative gene expression patterns, we

142 performed unbiased soft clustering and 3D visualization across the heart (Figure 2D). The analysis revealed 15 clusters of which 10 had specific enrichment of gene expression localised to one

144 anatomical compartment (e.g.: expression pattern restricted to vessels; atria; left or right ventricles).

145 Interestingly, 5 clusters contained gene sets with complex expression patterns across anatomical

146 sections (e.g.: expression pattern observed in atria, vessels and ventricular septum; atria and right

147 ventricle) (Figure 2D). These novel synexpression groups indicate complex molecular functions

148 shared across anatomical compartments (Table S2). Genes that are not spatially restricted (i.e.: highest

149 probability of belonging to a cluster is less than 0.7) were clustered together (Figure S2C) and the

150 observed average standardised expression was across all sections. Gene ontology (GO) analysis of

151 these gene sets identified enrichment of cellular maintenance processes, supporting the role of this

152 broadly expressed synexpression group in basic cellular functions (Figure S2D).

154 In summary, expected patterns of gene regulation in the murine heart were captured in our study and 155 novel patterns were also revealed. 


\section{Deciphering gene expression profiles of the atria}

158 We next investigated the spatio-transcriptional changes amongst the atrial sections. Three of the

159 previously identified 15 clusters revealed subsets of genes which were either up- (cluster 11, cluster 4)

160 or down-regulated (cluster 9) in the atria relative to the rest of the cardiac sections (Figure

$1613 \mathrm{~A})$. Genes belonging to cluster 11 were found to be enriched in biological processes relating to

162 extracellular structure, and those of cluster 4 were enriched in biological functions relating to

163 cardiovascular development and GTPase mediated signal transduction. Unsurprisingly genes of the

164 cluster associated to high gene expression in the ventricles was enriched in metabolic processes and

165 mitochondrial function (Figure 3B). The distinct atrial specific expression is represented by known

166 atrial markers (e.g.: Myl4, Myl7 (Orr et al. 2016), (Huang et al. 2003)) and novel ones (e.g.: Eps8,

167 Usp11), whereas Myl2 and Adrala are respectively known and unknown markers showing ventricular

168 specific expression patterns (Figure 3C). We further validated Myl4 in silico expression gene patterns

169 by RNAScope in situ hybridization (Figure 3D). As expected, Myl4 displayed high expression in both

170 atria. We have also shown the DAPI negative control (Figure S2E), as well as an RNAScope in situ

171 hybridization of $U b c$, a highly expressed cardiac marker discovered in our analysis (Figure 3E, Figure

172 2SF) to confirm our findings. We also validated the expression of the cluster 9 gene Adrala, and

173 confirmed the transcript was restricted to ventricles (Figure S2H-I). Even though the relative

174 expression of Adrala was low, higher expression was still observed in ventricle, which demonstrated

175 the sensitivity of our analysis.

176

177 We then investigated gene expression differences between the left and the right atria. No specific

178 synexpression groups from the soft-clustering could capture differences between the atria. Thus, we

179 performed a supervised DGE analysis between the left and right atria, and identified markers for each

180 atrium (Figure 3E). The left atrium was characterised by known markers such as left cardiac lineage

181 marker Pitx2 (Campione et al. 2001) and the right atrium by the sinoatrial node transcription factor 
182 Tbx3 (Hoogaars et al. 2007) (Figure 3F). Consistent with this, KEGG pathway analysis of the

183 identified DGE revealed enrichment of TGF-beta signalling, neuroactive ligand-receptor interaction

184 and calcium signalling pathways in the right atrium (Figure S2F). In addition, comparative analysis of

185 the molecular functions differentially recruited between the left or the right atrium suggested that

186 extracellular matrix (ECM) functions (driven by well-known ECM components such as Hmcn2,

187 Adamts 8 ) are highly enriched in the left atrium (Figure 3G). In contrast, cytokine binding and channel

188 activity was enriched in the right atrium (exemplified by markers such as Lepr, Kcnc2, Hcn4).

189 Collectively, our findings provide insight into the specific transcriptional attributes of the atria where

190 major expression differences pertain to the pacemaker functions restricted to the right atrium.

In order to examine gene expression differences within the ventricular regions, we performed CoA on the ventricular sections exclusively (Figure 4A). Distribution of the section within the first two components revealed a tight clustering of the left ventricular sections away from the right ventricular sections, with the exception of the right, apical ventricular section (RV_E), which clustered closer to the LV sections. Soft clustering confirmed this distribution and identified two clusters containing genes which were highly expressed in the left ventricle (Figures 4B,C; clusters 15 and 7) and one cluster (Cluster 10) containing genes with higher expression in the right ventricle (Figure 4D). The CoA analysis also allowed us to determine which genes caused most of the variability in the ventricles (Figure 4A). These include Nppb Efr3b, Brcal, Nrn1, Ces2e and Plekhh1 as enriched in the left ventricle and Itga2b, Ngp and Tubbl in the right ventricle (Figure 4E). Furthermore, as validation, we performed RNAscope in situ hybridization of Nppb expression (Figure S2K). Supervised DGE analysis between the left and right ventricular segments confirmed the findings using clustering analysis (Figure 4F). Indeed, we found a similar pattern of separation with the cardiac sections when we conducted hierarchical clustering using the genes with the highest log fold changes from our DGE analysis (Figure 4F). The genes with the highest log fold changes are common to the top genes from 
our CoA and soft cluster analysis, such as, Itga2b, Tubbl, Nppb, and Plekhh1. Intriguingly, we found

209 that the top genes of the right ventricle regulate processes such as wound healing and blood 210 coagulation (Table S1).

212 To further delve into the transcriptional complexity of the ventricles, we investigated additional

213 sources of variation within the dataset. For this, we examined components 5 and 6 of the ventricular sections in the CoA (Figure 5A). We identified three clustered groups of sections corresponding to a unique spatial transcriptional pattern. These revealed that the inferior sections of the right ventricle

216 (RV_C, RV_D, RV_E) segregate with the superior sections of the left ventricle (LVA_B, LVP_B,

217 LVL_B). On the other hand, the superior section of the right ventricle (RV_B) clusters together with

218 the remaining ventricular sections. The inferior section of the septum (LVC_D) surprisingly segregates away from both groups (Figure 5A). We then performed c-means clustering to further study these differences, which also revealed two similar clusters of complex patterns of gene expression across the two ventricles (Figures 5B). Interestingly both clusters show the inferior portion of the septum (LVC-D) to have very low gene expression in contrast to its neighbouring sections. This analysis provides a novel appreciation of the molecular differences within the two ventricles.

\section{Prediction of non-myocyte localization within the heart}

The novel spatial patterns discovered in this study lead us to investigate whether the molecular differences between the organ sub-compartments are due to their different functions and cell compositions. In order to address this, we mined the cell-specific markers unbiasedly identified by markers from each cell type across all ventricular sections to generate a cell signature that we then superimposed in our 3D model. This in turn allowed us to locate where each cell type was most likely to be present in the ventricular sections and revealed that cell types are uniformly distributed across sections (Figure S2H). To further appreciate the spatial restrictions of different cardiac cellular 
234 subtypes in our 3D digital map, we repeated this procedure for the whole heart, performed

235 hierarchical clustering and visualized the predicted locations of cell types within the heart (Figure

236 5E). Our analysis confirmed spatial enrichment of distinct cell-types in specific areas of the heart. For

237 example, the spatial profiles of the two fibroblast subtypes differ from each other. Markers of

238 fibroblasts type 2 display restricted expression in the vessels and atria, whereas fibroblasts type 1 are

239 more widely distributed in heart. The most similar spatial expression profiles between two cell types

240 are those of pericytes and endothelial cells, and of fibroblast 1 and macrophages. The novel spatial

241 patterns of transcription identified, provide an insight into potentially new structural understanding of

242 the organ.

In order to make the transcriptome analysis and visualization of the 3D model accessible to a wider clusters from this study, and DGE analysis features (Figure 6A). In addition, a custom set of genes may be uploaded (for example single-cell markers), and the system will in turn extract a gene expression signature by performing an averaged expression of those genes for each section across the entire heart. The 3D model can be rotated or expanded for the examination of spatial patterns of gene expression (Figure 6B). The right panel displays this information for the current gene, sorted by the absolute descending value of the Pearson coefficient of determination (expressed as a percentage), giving the user genes which have RNA expression levels most correlated and inversely correlated with their current gene of interest (Figure 6C), allowing the identification of synexpression groups.

257 For the first time, a 3D interface for exploring spatial gene expression offers real time differential 258 gene expression analysis. Comparisons between any two sets of cardiac sections can be performed 
260 "Compare" allows the input of the first set (which may include more than one sub-compartment),

261 which can be selected by clicking on the model (Figure 6D). Finally, data can be visualized using two

262 colour modes (Figure 6E) facilitating the website accessibility. In summary, our tool offers an ease of

263 analysis and visualization of the adult mouse transcriptome, which could be applicable to any other

264 organ or tissue 3D model.

265

\section{Discussion}

267 Our study presents a novel way to integrate high-throughput data on a three-dimensional model for

268 analysis. We have demonstrated an alternative and beneficial method for data visualization of gene

269 expression data in 3D of an organ, alongside conventional approaches. For example, in our soft

270 cluster analysis, we have provided the standardised gene expression line graphs concurrent to the

271 cluster expression means visualized on the 3D heart. Similarly we have also provided the localisation

272 predictions of numerous cell types in both the 3D model and via a heatmap. In both of these cases,

273 the contrasting expression profiles between the clusters, or the different cell types is evident in both

274 visualization approaches, however, the 3D heart poses as a more intuitive form for visualization in the

275 complex spatial context.

276 The online tool we have created is advantageous, as expression profiles of sufficiently expressed

277 genes or groups of genes in the heart can be visualized, as well as corresponding correlated genes.

278 Additionally, our tool effortlessly allows for differential gene expression analysis, and visualization.

279 Furthermore, the easily accessible tool can be freely used for visualization and analysis of cardiac

280 related gene expression, which is beneficial for hypothesis building and uncovering of new roles of

281 gene expression in the mammalian heart.

283 Our spatial transcriptomic approach allowed us to show that most of the variability between the

284 cardiac sections is due to the difference between the atria, major vessels and ventricles. In the major 
found Ponl, a gene known to be associated with atheroprotective effects and regulation of

287 cardiovascular disease (Tward et al. 2002), (Shih et al. 1998). Similarly, Adipoq, which is also known

288 to affect the artery intima media thickness (Patel et al. 2008), displays high expression in the major

289 vessels. In conjunction with our findings, Adipoq is also present in aortic endothelial cells $\underline{\text { Komura et }}$

290 al. 2013), hence this three-dimensional model serves well for hypothesis testing of other potentially

291 present proteins previously not associated with any of the cardiac sub-components. We also

292 uncovered known and unknown markers for the atria and ventricles, such as Myl4 or Myl3

293 respectively (Gudbjartsson et al. 2017) (Peng et al. 2017) (Orr et al. 2016). Myl3 has been known to

294 be associated with all sub-compartments of the heart, however the degree of differential expression

295 across compartments had been masked by the lack of spatial information (T. Y. Wang et al. 2018).

296 Differential gene expression analysis between left and right atria revealed enrichment of $T b x 3$ expression in the right atrium, a crucial transcription factor governing the establishment of the sinoatrial node, also located in the right atrium. Not surprising, the most distinct ventricular pattern was between the left and the right chambers. The left ventricle was found to be enriched in functions associated to muscle regulatory processes such as higher respiratory and muscle activity which is concordant to previous research, as the left ventricle is required to supply blood to the entirety of an organism. In contrast, the right ventricle pumps blood through, to the pulmonary vasculature, and only with about $25 \%$ of the stroke work of the left ventricle (Sordahl 1976) (Voelkel et al. 2006).

Beyond these major differences between atria and ventricles, we identified a unique set of spatial gene expression signatures. We hypothesised that the cellular composition between the sub-compartments contribute to the observed differences. To aid in our understating of the dominant cellular compositions retaining spatial information, we exploited our 3D model to map cell-type specific gene signatures across the heart. Interestingly we found endothelial cells and pericytes to have an approximately equivalent spatial distribution. The concurrence of these two cell-types has been

311 extensively established (Hellström et al. 2001) (Franco et al. 2011) (Kato et al. 2018) (Murray et al.

312 2017), hence it is captivating to find their 3D profiles correlate within the heart. This expected and 
314 revealed. Indeed, our single cell localisation hypotheses also suggested that $\mathrm{T}$ cells and B cells should

315 be enriched in the midline-transverse section of the right ventricle. Studies have previously shown

316 that the heart is comprised of cells from the hematopoietic lineage, however this novel link to a spatial

317 compartment uncovers new possibilities for the roles of these cells in the heart (Farbehi et al. 2019),

318 (Skelly et al. 2018), (Holzinger et al. 1996), (Pinto et al. 2016). This model holds as a suitable

319 benchmark for hypothesis testing of cardiac cellular localisations, and possible functions of the

320 various anatomical components.

322 Curiously, there were patterns indicating septal divergence from our CoA and cluster analyses, in

323 particular the section LVC-D appeared to have dissimilar expression to its neighbouring sections.

324 These findings align with some of the cell-type specific spatial profiles, which could account for the

325 distinction of LVC-D, in particular Schwann cells, the subset of fibroblasts identified by (Skelly et al.

326 2018) fibroblasts 1 and Macrophages. This difference, for instance, could be in consequence of the

327 discontinuity of the glial cell populations, which pass down through the septal region and then diverge

328 in the central region to the rest of the heart as Purkinje fibres (Anderson et al. 2009).

329

330 We have also uncovered upregulated genes in the superior region of the heart in comparison to the

331 other ventricular sections. It was riveting to discover that fibroblasts 1 and macrophages had a

332 hypothesised concentration in the apex of the heart, as well as an almost identical spatial profile. In

333 the context of cardiac regeneration this is very enticing as both fibroblasts and macrophages are

334 known to communicate extensively post myocardial infarcts (MI)s and jointly play a substantial role

335 in cardiac repair, by promoting debris clearance and the establishment of the fibronectin matrix.

336 (Sattler \& Rosenthal 2016) (Chen et al. 2012) (Forte et al. 2018). It would be very intriguing to find

337 that their communication is required for homeostatic cardiac function based on the evidence from our

338 study, however this is something yet to be investigated. 
340 Having drawn these conclusions, it is necessary to state that there are limitations in single cell studies

341 of the heart, which impacts our hypotheses on cardiac cellular localisation. (Skelly et al. 2018) have

342 only identified two subtypes of fibroblasts, however, (Farbehi et al. 2019) have identified more

343 subtypes in the adult mouse heart. The reason for this may be because more rare cell types were

344 captured in (Farbehi et al. 2019)'s study as only the apical section of the heart was isolated, in

345 comparison to (Skelly et al. 2018)'s, which utilised the entire ventricle. This shows that the use of the

346 3D-cardiomics tool, and hypotheses drawn from it could be subjective to prior analyses. Having the

347 spatial information of cell types throughout an organ tells us not only more about the role that these

348 cells may play in a homeostatic setting of the heart and how they maintain the organ, but we could

349 also gain a better understanding which cells function or communicate together, and hence possibly

350 further our understanding of these roles in other contexts such as cardiac injury and repair.

351

352 In summary, we propose that by retaining the spatial signature of the transcriptome of organs and in

353 combination with 3D models not only allows us to visualise expression patterns across an organ but

354 greatly enhances discovery. We anticipate that the capacity of 3D-Cardiomics to be combined with

355 single cell or pathological signatures will be of great utility to the cardiac field. 
358 Materials and Methods

Key resources table

\begin{tabular}{|c|c|c|}
\hline $\begin{array}{l}\text { REAGENT or } \\
\text { RESOURCE }\end{array}$ & SOURCE & IDENTIFIER \\
\hline \multicolumn{3}{|c|}{ Chemicals, Peptides, and Recombinant Proteins } \\
\hline $\begin{array}{l}\text { Absolute } \\
\text { Ethanol }\end{array}$ & Sigma-Aldrich & E7023 \\
\hline $\begin{array}{l}\text { Collagenase, } \\
\text { Type I }\end{array}$ & $\begin{array}{l}\text { Worthington } \\
\text { Biochemical } \\
\text { Corporation }\end{array}$ & LS004200 \\
\hline $\begin{array}{l}\text { Formalin } \\
\text { solution, neutral } \\
\text { buffered, } 10 \%\end{array}$ & Sigma-Aldrich & HT501128-4L \\
\hline $\begin{array}{l}\text { Hank's } \\
\text { Balanced Salt } \\
\text { Solution }\end{array}$ & $\begin{array}{l}\text { ThermoFisher } \\
\text { Scientific }\end{array}$ & 14175103 \\
\hline $\begin{array}{l}\text { Phosphate- } \\
\text { buffered Saline }\end{array}$ & $\begin{array}{l}\text { ThermoFisher } \\
\text { Scientific }\end{array}$ & 10010023 \\
\hline $\begin{array}{l}\text { Propidium } \\
\text { Iodide Solution }\end{array}$ & Sigma-Aldrich & P4864 \\
\hline \multicolumn{3}{|c|}{ Critical Commercial Assays } \\
\hline RNeasy Micro & QIAGEN & 74004 \\
\hline
\end{tabular}


bioRxiv preprint doi: https://doi.org/10.1101/792002; this version posted October 3, 2019. The copyright holder for this preprint (which was

not certified by peer review) is the author/funder, who has granted bioRxiv a license to display the preprint in perpetuity. It is made available under aCC-BY-NC-ND 4.0 International license.

\begin{tabular}{|c|c|c|}
\hline Kit & & \\
\hline $\begin{array}{l}\text { RNAscope } 2.5 \\
\text { LS Assay-RED }\end{array}$ & ACDBio & 322150 \\
\hline $\begin{array}{l}\text { TruSeq Stranded } \\
\text { Total RNA } \\
\text { Library Prep Kit }\end{array}$ & Illumina & RS-122-2201 \\
\hline \multicolumn{3}{|l|}{ Deposited Data } \\
\hline $\begin{array}{l}\text { Raw and } \\
\text { analyzed data }\end{array}$ & This paper & $\begin{array}{l}\text { RNA-seq data will be made publically available from the Gene } \\
\text { Expression Omnibus (GEO) upon the acceptance of the manuscript. }\end{array}$ \\
\hline $\begin{array}{l}\text { RNA-seq } \\
\text { summarized files }\end{array}$ & This paper & $\begin{array}{l}\text { The summarized RNA-seq files will be made publically available upon } \\
\text { the acceptance of the manuscript. }\end{array}$ \\
\hline \multicolumn{3}{|c|}{ Experimental Models: Organisms/Strains } \\
\hline $\begin{array}{l}\text { Mouse: } \\
\text { Wildtype } \\
\text { C57/BL6 female } \\
\text { adult }\end{array}$ & N/A & N/A \\
\hline $\begin{array}{l}\text { Mouse: } \\
\text { Wildtype } \\
\text { C57BL/6J }\end{array}$ & 000664 JAX & N/A \\
\hline & & \\
\hline
\end{tabular}


bioRxiv preprint doi: https://doi.org/10.1101/792002; this version posted October 3, 2019. The copyright holder for this preprint (which was

not certified by peer review) is the author/funder, who has granted bioRxiv a license to display the preprint in perpetuity. It is made available under aCC-BY-NC-ND 4.0 International license.

\begin{tabular}{|c|c|c|}
\hline Oligonucleotide & & \\
\hline $\begin{array}{l}\text { RNAscope } 2.5 \\
\text { VS Probe- Mm- } \\
\text { Myl4 }\end{array}$ & ACDBio & 443809 \\
\hline $\begin{array}{l}\text { RNAscope } 2.5 \\
\text { VS Probe- Mm- } \\
\text { Adra1a }\end{array}$ & ACDBio & 408619 \\
\hline $\begin{array}{l}\text { RNAscope } 2.5 \\
\text { VS Probe- Mm- } \\
\text { Nppb }\end{array}$ & ACDBio & 425029 \\
\hline $\begin{array}{l}\text { RNAscope } 2.5 \\
\text { VS Probe- Mm- } \\
\text { Ubc }\end{array}$ & ACDBio & 312018 \\
\hline
\end{tabular}

Software and Algorithms

\begin{tabular}{|l|l|l|}
\hline Amira & (ThermoFisher & https://www.fei.com/software/amira-for-life-sciences/ \\
& Scientific, 2019) & \\
\hline ComplexHeatma & $\underline{\text { (Gu et al. 2016) }}$ & https://bioconductor.org/packages/release/bioc/html/ComplexHeatmap. \\
& $\underline{\text { html }}$ \\
\hline EdgeR & $\underline{\text { (Robinson et al. }}$ & http://bioconductor.org/packages/release/bioc/html/edgeR.html \\
& $\underline{\text { (McCarthy et al. }}$ & \\
\hline FastQC & $\underline{2012)}$ & \\
\hline
\end{tabular}


bioRxiv preprint doi: https://doi.org/10.1101/792002; this version posted October 3, 2019. The copyright holder for this preprint (which was

not certified by peer review) is the author/funder, who has granted bioRxiv a license to display the preprint in perpetuity. It is made available under aCC-BY-NC-ND 4.0 International license.

\begin{tabular}{|c|c|c|}
\hline & Others 2010) & \\
\hline GOPlot & $\begin{array}{l}\text { (Walter et al. } \\
\underline{2015)}\end{array}$ & https://CRAN.R-project.org/package=GOplot \\
\hline ggplot2 & (Wickham 2016) & https://CRAN.R-project.org/package=ggplot2 \\
\hline ggrepel & $\begin{array}{l}\text { (Slowikowski } \\
\underline{2016)}\end{array}$ & $\underline{\text { https://CRAN.R-project.org/package=ggrepel }}$ \\
\hline HTSeq & $\begin{array}{l}\text { (Anders et al. } \\
\underline{2010)}\end{array}$ & $\underline{\text { https://htseq.readthedocs.io/en/release } 0.10 .0 /}$ \\
\hline Made4 & $\begin{array}{l}\text { (Culhane et al. } \\
\underline{2005)}\end{array}$ & http://bioconductor.org/packages/release/bioc/html/made4.html \\
\hline Maya & (Autodesk, 2019) & https://www.autodesk.com.au/products/maya/overview \\
\hline Metascape & $\begin{array}{l}\text { (Tripathi et al. } \\
\underline{2015)}\end{array}$ & http://metascape.org/ \\
\hline Mfuzz & $\begin{array}{l}\text { (Futschik \& } \\
\text { Carlisle 2005) }\end{array}$ & https://bioconductor.org/packages/release/bioc/html/Mfuzz.html \\
\hline Panther & & \\
\hline Samtools & $\underline{(\mathrm{Li} \text { et al. 2009) }}$ & http://samtools.sourceforge.net/ \\
\hline STAR & $\begin{array}{l}\text { (Dobin et al. } \\
\underline{2013)}\end{array}$ & https://github.com/alexdobin/STAR \\
\hline treemap & (Tennekes 2013) & https://CRAN.R-project.org/package=treemap \\
\hline Trimmomatic & $\begin{array}{l}\text { (Bolger et al. } \\
\underline{2014)}\end{array}$ & http://www.usadellab.org/cms/?page=trimmomatic \\
\hline Unity & Unity & $\underline{2018.3 .10 \mathrm{f} 1}$ \\
\hline
\end{tabular}




\begin{tabular}{|c|c|c|}
\hline & $\begin{array}{l}\text { Technologies } \\
\underline{\text { (https://unity.co }} \\
\underline{\mathrm{m})}\end{array}$ & \\
\hline Other & & \\
\hline $\begin{array}{l}\text { Automatic cell } \\
\text { counter EVE }\end{array}$ & NanoEnTek & EVE-MC \\
\hline $\begin{array}{l}\text { Bio-Gen } \\
\text { PRO200 } \\
\text { Homogenizer }\end{array}$ & PRO Scientific & $01-01200$ \\
\hline $\begin{array}{l}\text { BOND RX Fully } \\
\text { Automated } \\
\text { Research Stainer }\end{array}$ & Leica Biosystems & 21.2821 \\
\hline $\begin{array}{l}\text { Mouse Heart } \\
\text { Slicer Matrix }\end{array}$ & $\begin{array}{l}\text { ZINC } \\
\text { Instruments }\end{array}$ & HSMS005-1 \\
\hline
\end{tabular}

363 Contact for reagent and resource sharing

364 Further information and requests for resources and reagents should be directed to and will be fulfilled

365 by Lead Contact Jose Polo (jose.polo@monash.edu). 
370 For the sequencing experiment, C57/BL6 mice were housed at the Monash University animal facility

371 in strict accordance with good animal practices defined by the National Health and Medical Research

372 Council (Australia) Code of Practice for the Care and Use of Animals for Experimental Purposes. All experimental procedures were performed under the approval of the Monash University Animal Research Platform animal ethics committee. For the in vivo validations, C57BL/6J from JAX, were used with good animal practices defined by the Public Health Service Policy on the Humane Care and

376 Use of Laboratory Animals and the Guide for the Care and Use of Laboratory animals; in compliance

377 with all federal, state and local guidelines, regulations and animal care programs, fully accredited by

378 the Association for the Assessment and Accreditation of Laboratory Animal Care International.

\section{Method details}

\section{Heart extraction and microdissection}

382 Mice of approximately 6-10 weeks of age were culled using the cervical dislocation method, then

383 sprayed with $80 \% \mathrm{v} / \mathrm{v}$ ethanol and immediately dissected through the abdomen under the sternum.

384 Once the diaphragm was dissected away to access the upper abdominal cavity, the rib cage was cut and lifted to expose the heart and lungs. Perfusion was then performed on the heart. Firstly small incisions were made on each lobe of the liver to aid in bloodletting. Hanks' Balanced Salt Solution was delivered through the left ventricle for one minute, using a $10 \mathrm{~mL}$ syringe with a 26-gauge needle. Hearts were removed by grasping the heart by the root and cutting through the major vessels and surrounding connective tissue. Once removed, the heart was placed in $310 \mathrm{mO}$ Phosphate Buffered Solution (PBS) to clean up excess fat, connective tissue, lungs thymus and trachea. 
392 The isolated hearts were first dissected using Vannas scissors to remove the atria and major vessels.

393 Each ventricle was then microdissected into four equidistant transverse sections with a mouse heart

394 slicer matrix. An anchor blade was used at the superior end of the heart to ensure the heart did not

395 move. The blades were firmly pressed down simultaneously to cut through the ventricles. All sections

396 were then placed into PBS and individually dissected into the sections as specified in Figure 1C with

397 Vannas scissors.

398

399

Tissue preparation

400

The microdissected sections of each heart were placed in $250 \mu 1$ Buffer RLT as supplied by QIAGEN

401

RNeasy Micro Kit. Six samples were processed at a time whilst the remaining sections were stored at

402

$-80^{\circ} \mathrm{C}$. The samples were homogenised for 30 seconds at medium speed (setting 2). The homogeniser

403 was cleaned with $80 \% \mathrm{v} / \mathrm{v}$ ethanol for 15 seconds, and then with deionised water for 15 seconds. The

404 samples were then immediately processed for RNA extraction.

405

406

RNAScope in situ hybridization

407

Hearts were fixed in 10\% neutral buffered formalin (Sigma-Aldrich), processed for paraffin

408 embedding and $5 \mu \mathrm{M}$ longitudinal sections used for automated staining with RNAscope $2.5 \mathrm{LS}$ Reagent Kit—Red (ACDBio) on a Leica Biosystems' BOND RX Research Advanced Staining System (Leica). Probes used were as follows: Myl4 443809; Adrala 408619; Nppb 425029 and positive control Ubc 312018.

412

\section{RNA sequencing}

414 RNA extraction and purification of all samples was done using the RNeasy Micro Kit according to

415 manufacturer's instructions. An illumina TruSeq Stranded Total RNA kit was used to prepare the 
416 libraries for poly-A enrichment of mRNA. For sample amplification, 15 PCR cycles were used,

417 standard to the Illumina kit protocol. RNA sequencing was performed on an Illumina NextSeq500.

418 Each library was paired-end with $75 \mathrm{bp}$ reads, as well as 20 million reads per sample.

419

421 Amira was used to export the 3D graphical model of the adult mouse heart [reference Ruijter] into

422 Wavefront .obj files, which could then subsequently be used with 3D modeling software Maya (2015)

423 to perform the computational slicing and sectioning. For this, the heart was first sliced into 5 transverse pieces as with the biological samples. Slicing of the 3D model was done using the "Slice" tool in Maya, which allows a straight line to be drawn to cut the object completely through. Each slice

426 was then 'sealed' to give the appearance of solid tissue. The 'sealing' of the slices was done by

427 adding faces individually to the model until the slice was completely covered. Once sealed, each slice

428 was then sectioned into 18 pieces, again using the Slice tool. Similar to the slicing process, each piece 429 was subsequently sealed by adding faces.

430

431

\section{User interface}

432 A visual system was developed to integrate RNA-seq datasets onto computational model pieces of the heart using the $\mathrm{C \#}$ programming language in the Unity environment. The program was compiled to

434 the WebGL platform to allow cross-platform accessibility through a web browser and fast data 435 retrieval. Source code is freely available on GitHub (https://github.com/Ramialison-Lab436 ARMI/3DCardiomics). For visualization purposes, the normalized values of gene expression observed 437 on the web interface were calculated by normalization to the local minimum and maximum 438 expression of the gene. 
441 Raw sequencing reads were filter/trimmed using trimmomatic (Bolger et al. 2014). Sequencing reads

442 were aligned to GENCODE's mouse reference genome (GRCm38 primary assembly, vM9

443 annotation) with STAR (v2.4.2a), (Dobin et al. 2013). Gene read counts were generated with HTSeq

444 (Anders et al. 2010). Genes with 1 count per million (CPM) in at least two of the samples were kept

445 for further analysis. For differential expression analyses, normalisation factors were calculated by the

446 trimmed means method using the EdgeR function calcNormfactors (Robinson et al. 2010). The glmFit

447 and glmLRT functions from the EdgeR package were used to perform differential gene expression

448 analysis. The design matrix required for these analyses included specification of heart segment and

449 batch label, in order to remove the batch effect. For the remainder of the analysis CPM values were

450 used throughout the study, and RPKM values were used for the cluster analysis. To remove the batch

451 effect for further analyses removeBatchEffect from EdgeR was used. The plotMDS function from

452 EdgeR was used for MDS analysis and visualisation. Made4 was utilised for CA (Culhane et al.

453 2005). Mfuzz was used for the soft cluster analysis. The number of clusters specified were determined

454 by the total number of dimensions explaining at least $95 \%$ of the variance in the data from the COA

455 on the dataset with RPKM values. Metascape was used for biological processes enrichment. The

456 treemap package was used for the treemap visualizations. All visualizations were made with ggplot2

457 unless otherwise specified. Unsupervised hierarchical clustering and the ComplexHeatmap map

458 package were used on significantly differentially expressed genes.

459

460

\section{Acknowledgements}

462 We would like to acknowledge the Histology and Microscopy Cores of the Jackson Laboratory for

463 performing the RNAScope experiments, the Ramaciotti Centre for Genomics for performing the NGS

464 experiments. We would also like to thank the Monash Animal Research Platform and Monash

465 Flowcore for providing required services throughout the course of the project. J.M.P. was funded by a

466 Sylvia-Charles Viertel Fellowship and an ARC Future Fellowship M.R. was funded by a 
NHMRC/Heart Foundation Career Development Fellowship and ARC Discovery Project Grant. A.T. was supported by a Biomedical Research Victoria UROP/CSL scholarship. The Australian

469 Regenerative Medicine Institute is supported by grants from the State Government of Victoria and the 470 Australian Government. Finally we would like to thank Dr. Jan Ruijter, Dr. Alexander Pinto, Ms. 471 Jeannette Hallab, Mr. Markus Tondl, Dr. Michael Eichenlaub, Dr. Anja Knaupp, Dr. Ethan Liu, Dr. 472 Jaber Firas, Dr. Sue Mei Lim, Dr. Sara Alaei, Dr. Gonzalo Del Monte-NIeto, the Ramialison 473 laboratory and the Polo laboratory for their valuable contributions to this study.

\section{Author Contributions}

476 J.M.P. conceived the study. J.M.P. and M.R. designed the experiments and co-lead the project and supervised the project together with F.J.R.. M.M. and F.J.R. performed the bioinformatics analysis, with contributions from N.M.T., A.T. and H.N.. M.M. interpreted the data with contributions from

479 N.T, A.T.. M.M. generated the figures with contributions from N.M.T., A.T., M.B.F., M.W.C. and 480 F.J.R.. N.T. performed the heart isolation with input from J.H., S.K.N., M.F. and M.W.C. and generated the transcriptional data and adapted the K.V.D. 3D model of the heart. A.T. developed and optimised the 3D-cardiomics user interface with contributions from N.M.T., A.P., D.P. and F.J.R.. M.F., M.W.C. generated the RNAscope datasets. M.M., F.J.R., M.R. and J.M.P. wrote the manuscript with contributions from N.M.T., A.T.. All authors approved of and contributed to the final version of the manuscript.

\section{Competing Interests}




\section{References}

492 Aanhaanen, W.T.J. et al., 2010. Developmental origin, growth, and three-dimensional architecture of

493 the atrioventricular conduction axis of the mouse heart. Circulation research, 107(6), pp.728-736.

494 Andersen, P.S. et al., 2012. A novel Myosin essential light chain mutation causes hypertrophic

495 cardiomyopathy with late onset and low expressivity. Biochemistry research international, 2012,

496 p.685108.

497 Anderson, R.H. et al., 2009. The anatomy of the cardiac conduction system. Clinical anatomy, 22(1),

498 pp.99-113.

499 Anders, S., Pyl, P.T. \& Huber, W., 2010. HTSeq: Analysing high-throughput sequencing data with

500 Python.

501 Andrews, S. \& Others, 2010. FastQC: a quality control tool for high throughput sequence data.

502 Asp, M. et al., 2017. Spatial detection of fetal marker genes expressed at low level in adult human

503 heart tissue. Scientific reports, 7(1), p.12941.

504 de Boer, B.A. et al., 2011. The interactive presentation of 3D information obtained from reconstructed

505 datasets and 3D placement of single histological sections with the 3D portable document ....

506 Available at: http://dev.biologists.org/content/138/1/159.short.

507 Bolger, A.M., Lohse, M. \& Usadel, B., 2014. Trimmomatic: a flexible trimmer for Illumina sequence

508 data. Bioinformatics, 30(15), pp.2114-2120.

509 Burkhard, S.B. \& Bakkers, J., 2018. Spatially resolved RNA-sequencing of the embryonic heart

510 identifies a role for $\mathrm{Wnt} / \beta$-catenin signaling in autonomic control of heart rate. eLife, 7 . Available at: http://dx.doi.org/10.7554/eLife.31515.

512 Campione, M. et al., 2001. Pitx2 expression defines a left cardiac lineage of cells: evidence for atrial

513 and ventricular molecular isomerism in the iv/iv mice. Developmental biology, 231(1), pp.252-264. 
514 Chen, J. et al., 2017. Spatial transcriptomic analysis of cryosectioned tissue samples with Geo-seq.

$515 \quad$ Nature protocols, 12(3), pp.566-580.

516 Chen, W. et al., 2012. Endogenous IRAK-M attenuates postinfarction remodeling through effects on

517 macrophages and fibroblasts. Arteriosclerosis, thrombosis, and vascular biology, 32(11), pp.2598-

5182608.

519 Culhane, A.C. et al., 2005. MADE4: an R package for multivariate analysis of gene expression data.

520 Bioinformatics, 21(11), pp.2789-2790.

521 Dobin, A. et al., 2013. STAR: ultrafast universal RNA-seq aligner. Bioinformatics, 29(1), pp.15-21.

522 Farbehi, N. et al., 2019. Single-cell expression profiling reveals dynamic flux of cardiac stromal,

523 vascular and immune cells in health and injury. eLife, 8. Available at:

524 http://dx.doi.org/10.7554/eLife.43882.

525 Forte, E., Furtado, M.B. \& Rosenthal, N., 2018. The interstitium in cardiac repair: role of the 526 immune-stromal cell interplay. Nature reviews. Cardiology, 15(10), pp.601-616.

527 Franco, M. et al., 2011. Pericytes promote endothelial cell survival through induction of autocrine

528 VEGF-A signaling and Bcl-w expression. Blood, 118(10), pp.2906-2917.

529 Futschik, M.E. \& Carlisle, B., 2005. Noise-robust soft clustering of gene expression time-course data.

530 Journal of bioinformatics and computational biology, 3(4), pp.965-988.

531 Garne, E. et al., 2007. Survival and Health in Liveborn Infants with Transposition of Great Arteries-

532 A Population-based Study. Congenital heart disease. Available at:

533 https://onlinelibrary.wiley.com/doi/abs/10.1111/j.1747-0803.2007.00093.x.

534 Gudbjartsson, D.F. et al., 2017. A frameshift deletion in the sarcomere gene MYL4 causes early-onset

535 familial atrial fibrillation. European heart journal, 38(1), pp.27-34. 
536 Gu, J.-Y. et al., 2012. Novel GATA5 loss-of-function mutations underlie familial atrial fibrillation.

537 Clinics, 67(12), pp.1393-1399.

538 Gu, Z., Eils, R. \& Schlesner, M., 2016. Complex heatmaps reveal patterns and correlations in 539 multidimensional genomic data. Bioinformatics , 32(18), pp.2847-2849.

540 Hellström, M. et al., 2001. Lack of pericytes leads to endothelial hyperplasia and abnormal vascular

541 morphogenesis. The Journal of cell biology, 153(3), pp.543-553.

542 Holzinger, C. et al., 1996. Are T cells from healthy heart really only passengers? Characterization of 543 cardiac tissue T cells. Immunology letters, 53(2-3), pp.63-67.

544 Hoogaars, W.M.H. et al., 2007. Tbx3 controls the sinoatrial node gene program and imposes

545 pacemaker function on the atria. Genes \& development, 21(9), pp.1098-1112.

546 Huang, C. et al., 2003. Embryonic atrial function is essential for mouse embryogenesis, cardiac

547 morphogenesis and angiogenesis. Development, 130(24), pp.6111-6119.

548 Junker, J.P. et al., 2014. Genome-wide RNA Tomography in the zebrafish embryo. Cell, 159(3), 549 pp.662-675.

550 Karaiskos, N. et al., 2017. The Drosophila embryo at single-cell transcriptome resolution. Science, $551358(6360)$, pp.194-199.

552 Kato, K. et al., 2018. Pulmonary pericytes regulate lung morphogenesis. Nature communications, $5539(1)$, p.2448.

554 Komura, N. et al., 2013. Adiponectin protein exists in aortic endothelial cells. PloS one, 8(8), 555 p.e71271.

$556 \mathrm{Li}, \mathrm{H}$. et al., 2009. The Sequence Alignment/Map format and SAMtools. Bioinformatics , 25(16), 557 pp.2078-2079. 
558 Massaia, A. et al., 2018. Single Cell Gene Expression to Understand the Dynamic Architecture of the

559 Heart. Frontiers in cardiovascular medicine, 5, p.167.

560 McCarthy, D.J., Chen, Y. \& Smyth, G.K., 2012. Differential expression analysis of multifactor RNA-

561 Seq experiments with respect to biological variation. Nucleic acids research, 40(10), pp.4288-4297.

562 Moorman, A.F.M. \& Christoffels, V.M., 2003. Cardiac chamber formation: development, genes, and

563 evolution. Physiological reviews, 83(4), pp.1223-1267.

564 Motoki, H. et al., 2009. Coagulation Activity is Increased in the Left Atria of Patients With

565 Paroxysmal Atrial Fibrillation During the Non-Paroxysmal Period. Circulation journal: official

566 journal of the Japanese Circulation Society, advpub, pp.0906100390-0906100390.

567 Murray, I.R. et al., 2017. Skeletal and cardiac muscle pericytes: Functions and therapeutic potential.

568 Pharmacology \& therapeutics, 171, pp.65-74.

569 Orr, N. et al., 2016. A mutation in the atrial-specific myosin light chain gene (MYL4) causes familial

570 atrial fibrillation. Nature Communications, $7(1) . \quad$ Available at:

571 http://dx.doi.org/10.1038/ncomms11303.

572 Patel, S. et al., 2008. Variation in the ADIPOQ gene promoter is associated with carotid intima media

573 thickness independent of plasma adiponectin levels in healthy subjects. European heart journal,

574 29(3), pp.386-393.

575 Peng, W. et al., 2017. Dysfunction of Myosin Light-Chain 4 (MYL4) Leads to Heritable Atrial

576 Cardiomyopathy With Electrical, Contractile, and Structural Components: Evidence From

577 Genetically-Engineered Rats. Journal of the American Heart Association, 6(11). Available at:

578 http://dx.doi.org/10.1161/jaha.117.007030.

579 Pinto, A.R. et al., 2016. Revisiting Cardiac Cellular Composition. Circulation research, 118(3), pp.400-409. 
581 Robinson, M.D., McCarthy, D.J. \& Smyth, G.K., 2010. edgeR: a Bioconductor package for

582 differential expression analysis of digital gene expression data. Bioinformatics, 26(1), pp.139-140.

583 Rodriques, S.G. et al., 2019. Slide-seq: A scalable technology for measuring genome-wide expression

584 at high spatial resolution. Science, 363(6434), pp.1463-1467.

585 Sattler, S. \& Rosenthal, N., 2016. The neonate versus adult mammalian immune system in cardiac

586 repair and regeneration. Biochimica et biophysica acta, 1863(7 Pt B), pp.1813-1821.

587 Shih, D.M. et al., 1998. Mice lacking serum paraoxonase are susceptible to organophosphate toxicity 588 and atherosclerosis. Nature, 394(6690), pp.284-287.

589 Siffel, C. et al., 2015. Survival of Children With Hypoplastic Left Heart Syndrome. Pediatrics, 590 136(4), pp.e864-70.

591 Skelly, D.A. et al., 2018. Single-Cell Transcriptional Profiling Reveals Cellular Diversity and 592 Intercommunication in the Mouse Heart. Cell reports, 22(3), pp.600-610.

593 Slowikowski, K., 2016. ggrepel: Repulsive text and label geoms for "ggplot2." R package version 0. $5946,5(11)$.

595 Sordahl, L., 1976. Differences in mitochondrial functions from right and left ventricular myocardium 596 of four mammalian species. Comparative biochemistry and physiology. B, Comparative biochemistry, 597 54(3), pp.339-342.

598 Ståhl, P.L. et al., 2016. Visualization and analysis of gene expression in tissue sections by spatial 599 transcriptomics. Science, 353(6294), pp.78-82.

600 Tennekes, M., 2013. treemap: Treemap visualization.

601 Tripathi, S. et al., 2015. Meta- and Orthogonal Integration of Influenza "OMICs" Data Defines a Role 602 for UBR4 in Virus Budding. Cell host \& microbe, 18(6), pp.723-735. 
603 Tward, A. et al., 2002. Decreased atherosclerotic lesion formation in human serum paraoxonase

604 transgenic mice. Circulation, 106(4), pp.484-490.

605 Voelkel, N.F. et al., 2006. Right ventricular function and failure: report of a National Heart, Lung, and

606 Blood Institute working group on cellular and molecular mechanisms of right heart failure.

607 Circulation, 114(17), pp.1883-1891.

608 Waardenberg, A.J. et al., 2014. Genetic networks governing heart development. Cold Spring Harbor 609 perspectives in medicine, 4(11), p.a013839.

610 Walter, W., Sánchez-Cabo, F. \& Ricote, M., 2015. GOplot: an R package for visually combining expression data with functional analysis. Bioinformatics , 31(17), pp.2912-2914.

612 Wang, T.Y. et al., 2018. Cardiomyocytes have mosaic patterns of protein expression. Cardiovascular

613 pathology: the official journal of the Society for Cardiovascular Pathology, 34, pp.50-57.

614 Wang, X. et al., 2018. Three-dimensional intact-tissue sequencing of single-cell transcriptional states.

615 Science, 361(6400). Available at: http://dx.doi.org/10.1126/science.aat5691.

616 Wickham, H., 2016. ggplot2: Elegant Graphics for Data Analysis, Springer.

617 Yue, X. et al., 2017. Heterogeneity of transverse-axial tubule system in mouse atria: Remodeling in

618 atrial-specific $\mathrm{Na}+\mathrm{Ca} 2+$ exchanger knockout mice. Journal of molecular and cellular cardiology, 619108, pp.50-60.

620 Zhi, Y. et al., 2016. Transcriptional analysis of atrial and ventricular muscles from rats. Genetics and 621 molecular research: GMR, 15(1). Available at: http://dx.doi.org/10.4238/gmr.15017330. 


\section{Supplemental Information}

\section{Supplementary table legends}

\section{Supplementary table1: CA and DGE analyses outputs}

627 The top 500 genes explaining most of the variability in the data of the CA, which included all cardiac

628 sections (sheet 1), with enriched biological processes (sheet 2); the top 500 genes of the CA analysis,

629 which included ventricular sections, in dimensions 1 and 2 (sheet 3) and respective biological

630 processes enriched (sheet 4); the top 500 genes of the CA analysis, which included ventricular

631 sections, in dimensions 5 and 6 (sheet 5) and respective biological processes enriched (sheet 6).

632 Finally, the DGE analysis outputs of the left atria compared to the right (sheet 7) and the right

633 ventricle compared to the left (sheet 8).

\section{Supplementary table 2: Soft cluster analysis outputs}

635 Outputs of the soft cluster analysis. Firstly, a list of all of the genes belonging to a cluster with a

636 probability of at least 0.7 (sheet 1 ). The remaining sheets include biological processes enriched for 637 each of the clusters.

638

639

640

641

642

643

644

645 
bioRxiv preprint doi: https://doi.org/10.1101/792002; this version posted October 3, 2019. The copyright holder for this preprint (which was not certified by peer review) is the author/funder, who has granted bioRxiv a license to display the preprint in perpetuity. It is made available under aCC-BY-NC-ND 4.0 International license.

648

649

650

651

652

653

654

655

656

657

658

659

660 
bioRxiv preprint doi: https://doi.org/10.1101/792002; this version posted October 3, 2019. The copyright holder for this preprint (which was

not certified by peer review) is the author/funder, who has granted bioRxiv a license to display the preprint in perpetuity. It is made available under aCC-BY-NC-ND 4.0 International license.

\section{Figures}

\section{Figure 1}
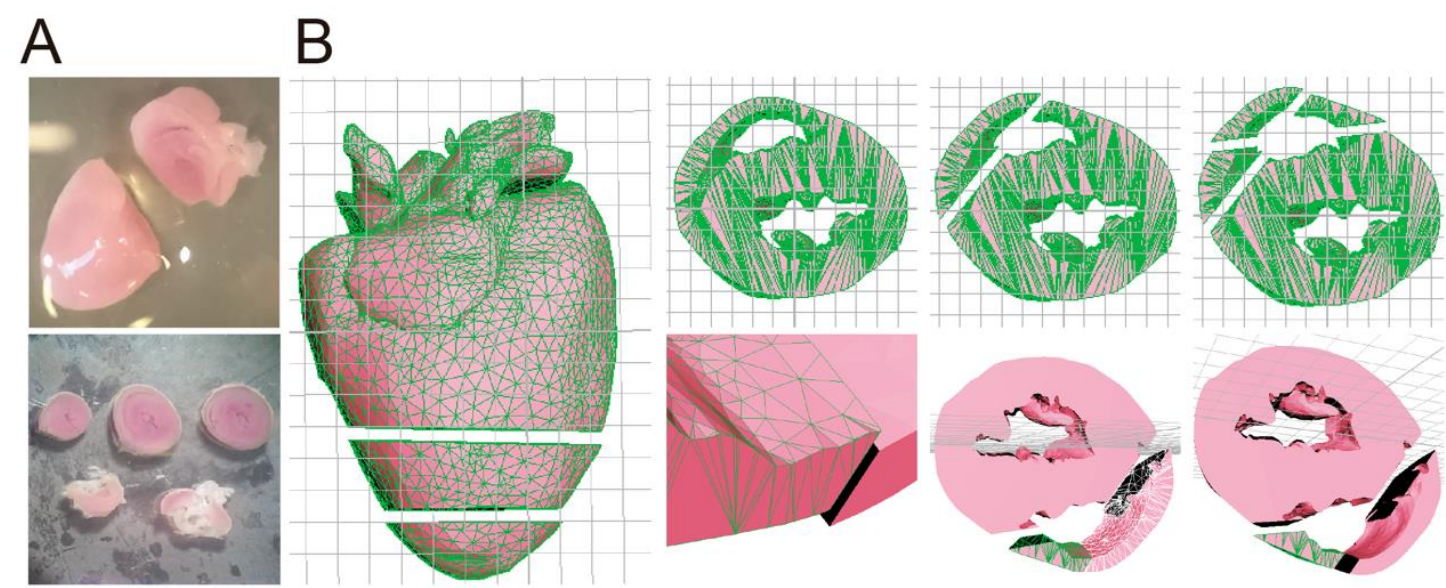

C
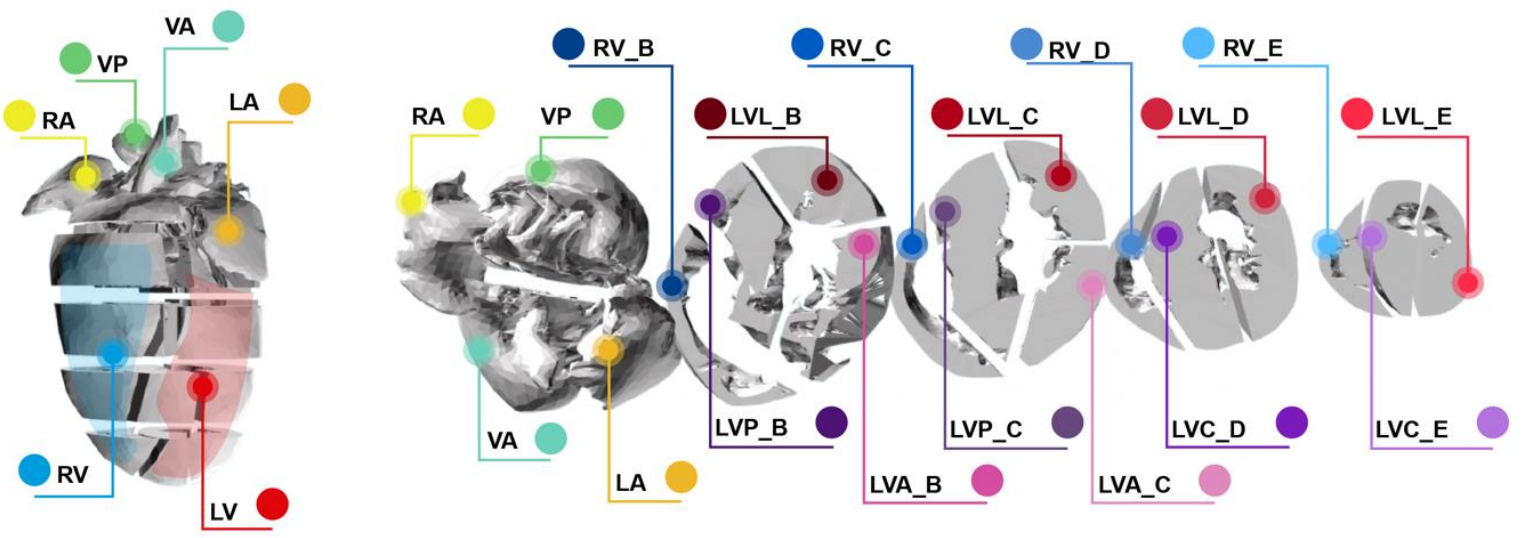
664 Figure 1: Schematic for designing the 3D-cardiomics interface, and

666 A) Microdissection of the mouse heart. The atria and vessels were first sectioned from the ventricle

667 (top), followed by sectioning of the ventricular pieces (bottom). B) in silico sectioning of the 3D

668 murine cardiac model in Maya. C) Nomenclature for combinations of the specific sections and for

669 each section of the heart model. Nomenclature: $\mathrm{VP}=$ vessel posterior, $\mathrm{VA}=$ vessel anterior, $\mathrm{RA}=$

670 right atrium, $\mathrm{LA}=$ left atrium, $\mathrm{RV}=$ right ventricle, $\mathrm{LV}=$ left ventricle, $\mathrm{LVP}=$ left ventricle posterior,

$671 \mathrm{LVA}=$ left ventricle anterior, $\mathrm{LVC}=$ left ventricle centre, $\mathrm{LVL}=$ left ventricle left. The ventricle was

672 sectioned into 4 larger sections which were B, C, D, E in order from the superior part of the ventricle

673 to the inferior.

674 
675 Figure 2
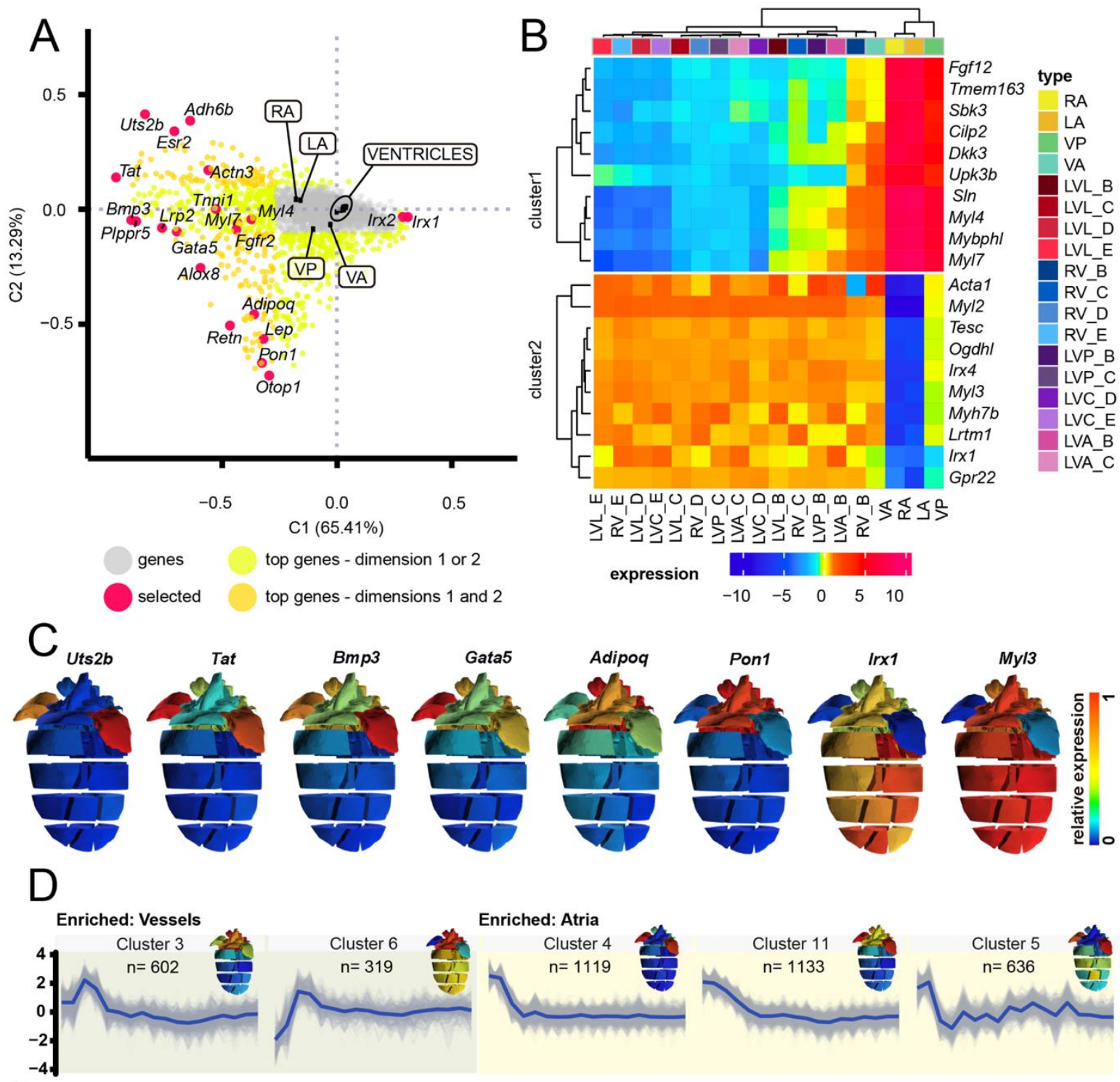

Enriched: Atria
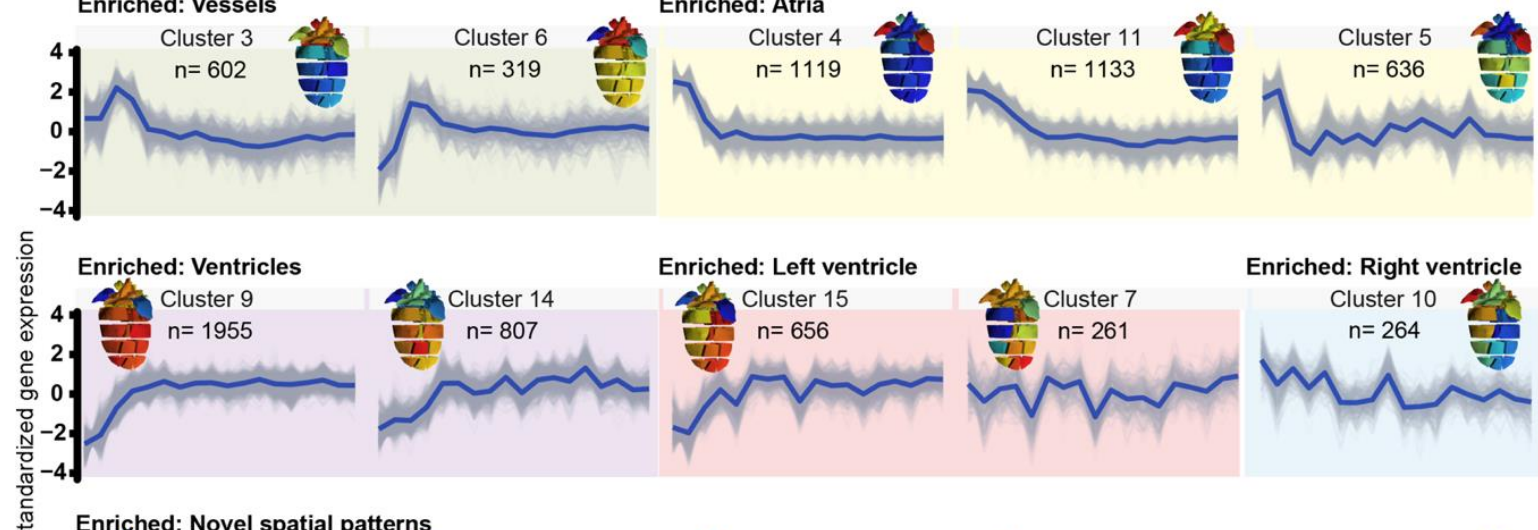

Enriched: Left ventricle
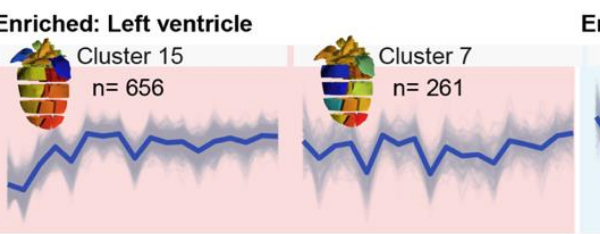

Enriched: Right ventricle
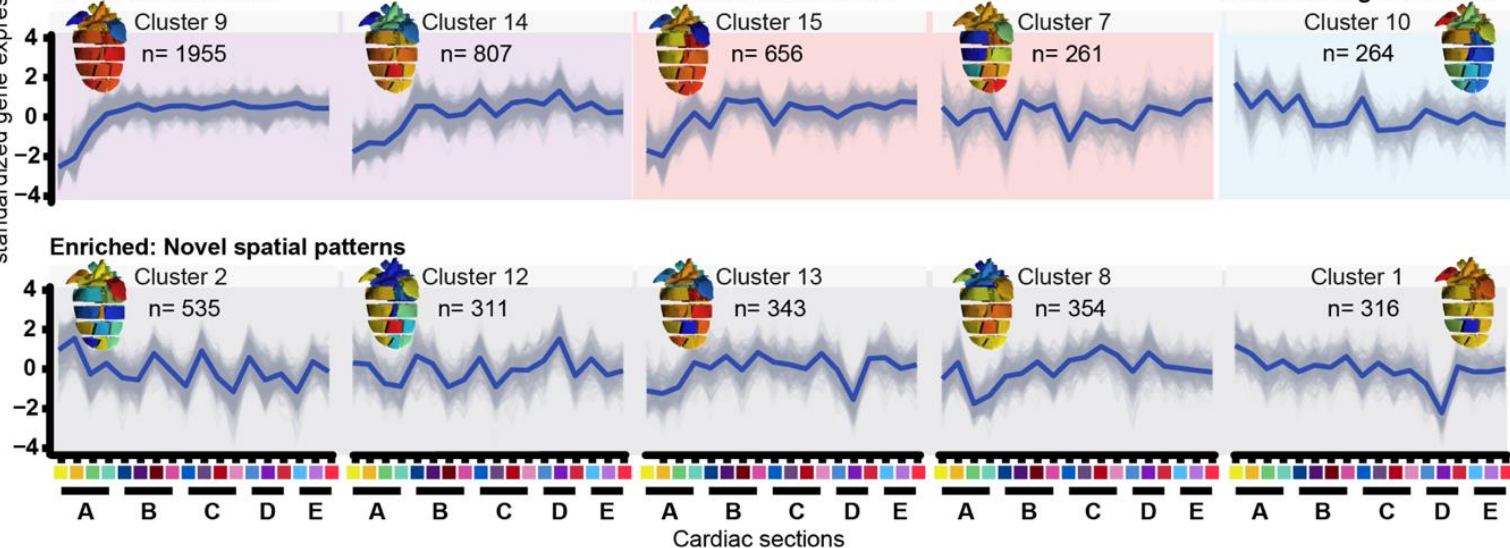

A $\quad$ B C 
677 Figure 2: Characterization of gene expression across the mouse heart

678 A) Biplot, visualizing the separation of all genes and all sections in the first two components of CoA.

679 Genes highlighted are the top 500 genes contributing to the most variance in components one and the

680 top 500 genes in component two. B) Heatmap depicting hierarchical clustering of all cardiac sections

681 and significant differentially expressed genes (atria and vessels against ventricles) with the highest

682 absolute $\log \mathrm{FC}$ values. C) Gene expression profiles of selected genes from the biplot visualized with

683 the 3D-cardiomics user interface tool. D) Soft clusters of cardiac gene expression in mouse,

684 represented in 2D and 3D.

685 
bioRxiv preprint doi: https://doi.org/10.1101/792002; this version posted October 3, 2019. The copyright holder for this preprint (which was not certified by peer review) is the author/funder, who has granted bioRxiv a license to display the preprint in perpetuity. It is made available under aCC-BY-NC-ND 4.0 International license.

Figure 3
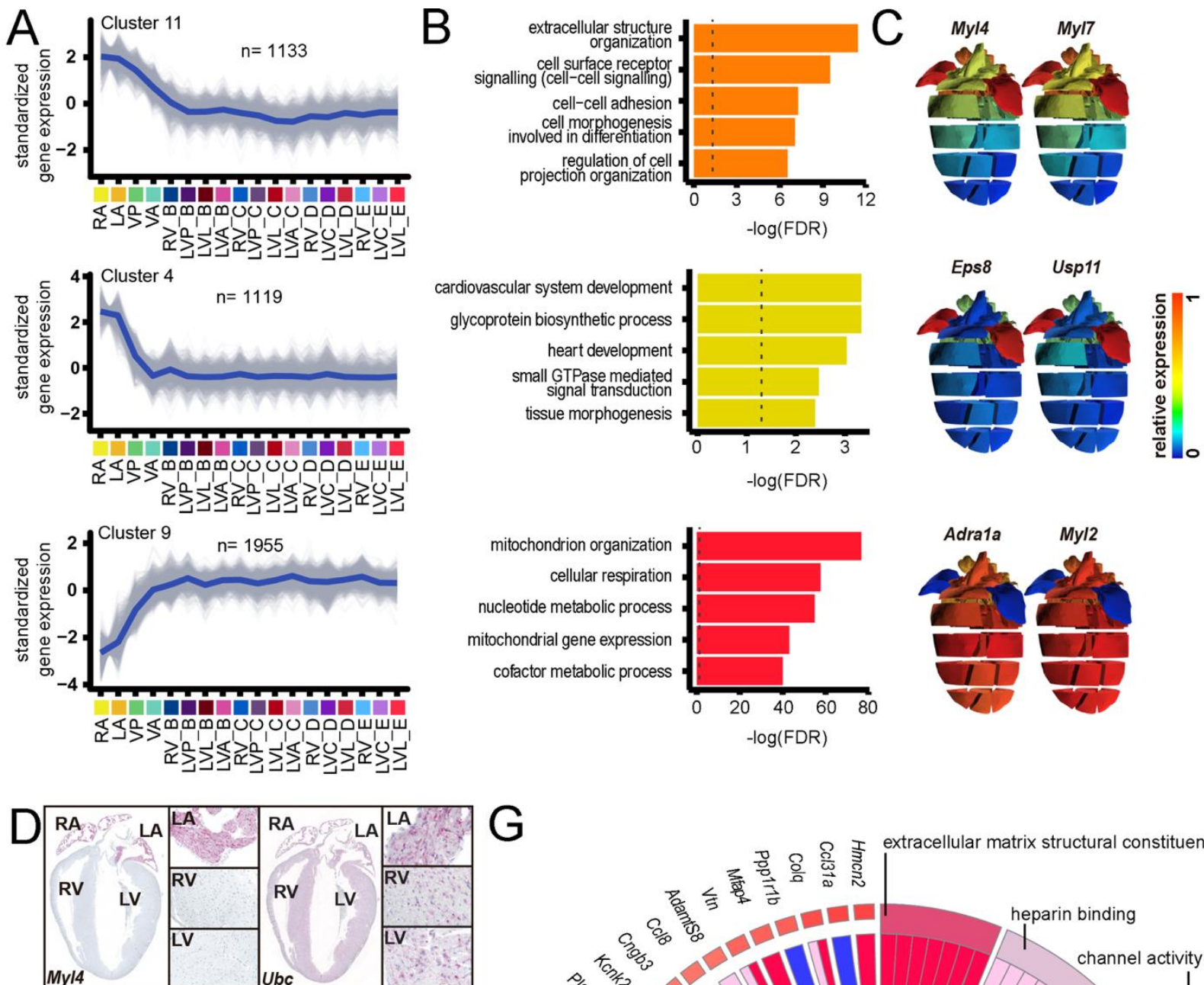

G

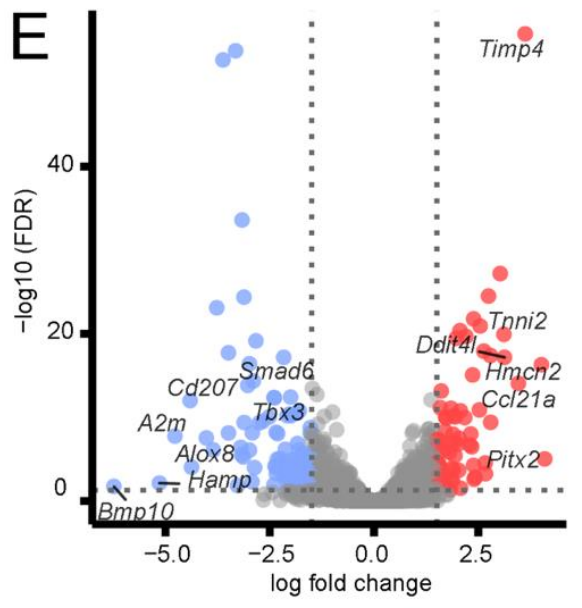

F
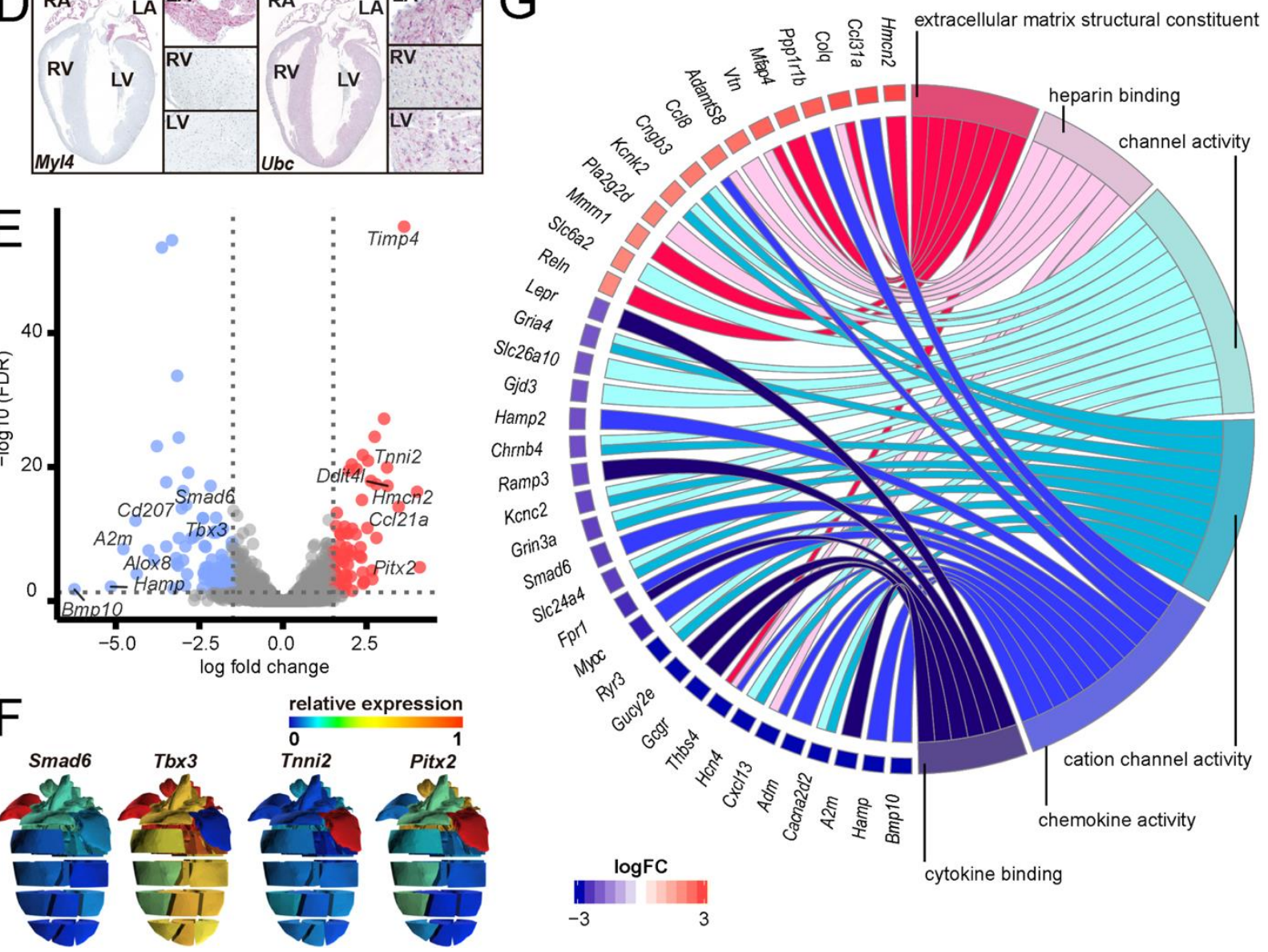
689 A) Soft clusters that contain genes describing the major differences between the atria and ventricles.

690 B) The respective biological processes and C) selected gene expression profiles for soft clusters 11, 4

691 and 9. D) RNA-scope in situ hybridization of atrial specific gene Myl4 which had been identified in

692 clusters 4 and the highly expressed gene $U b c$. Whole heart section is at $2.5 \mathrm{X}$ magnification and partial

693 sections were at 10X magnification. E) Volcano plot of differentially expressed genes from DGE

694 analysis of the left atria against the right. F) Gene expression profiles for several selected

695 differentially expressed genes between the left and right atria. G) Circos diagram depicting

696 differentially expressed genes with their log fold change, linked to one or more of the most enriched

697 molecular functions of the DGE analysis.

698

699

700

701

702

703

704

705

706

707

708 
710 Figure 4
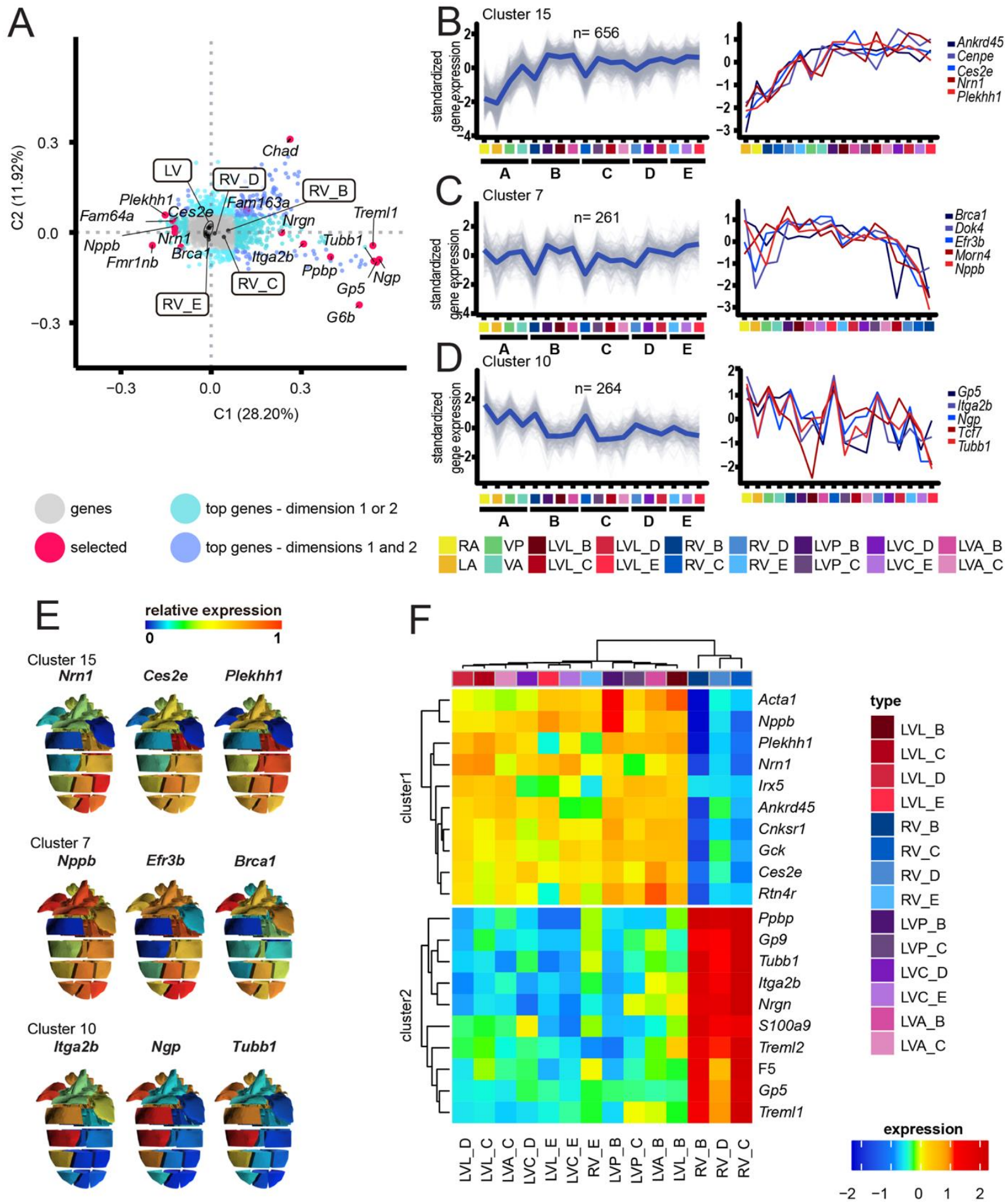
712 Figure 4: Transcriptional differences between the left and right ventricles

713 A) Biplot, visualizing the separation of all genes and all ventricular sections in the first two

714 components of CoA. Genes highlighted are the top 500 genes contributing to the most variance in

715 components one and the top 500 genes in component two. B-D) Soft clusters consisting genes highly

716 expressed in the left ventricle $(B, C)$ or the right ventricle (D), as well as gene expression profiles for

717 selected genes from their respective cluster (sections of the selected genes plots were rearranged in

718 the x-axis to clearly show the major differences between the ventricles). E) Selected gene expression

719 profiles in 3D from respective clusters in B-D). F) Heatmap depicting hierarchical clustering of all

720 cardiac sections and significant differentially expressed genes (right against left ventricle) with the

721 highest absolute $\log \mathrm{FC}$ values. 
723 Figure 5
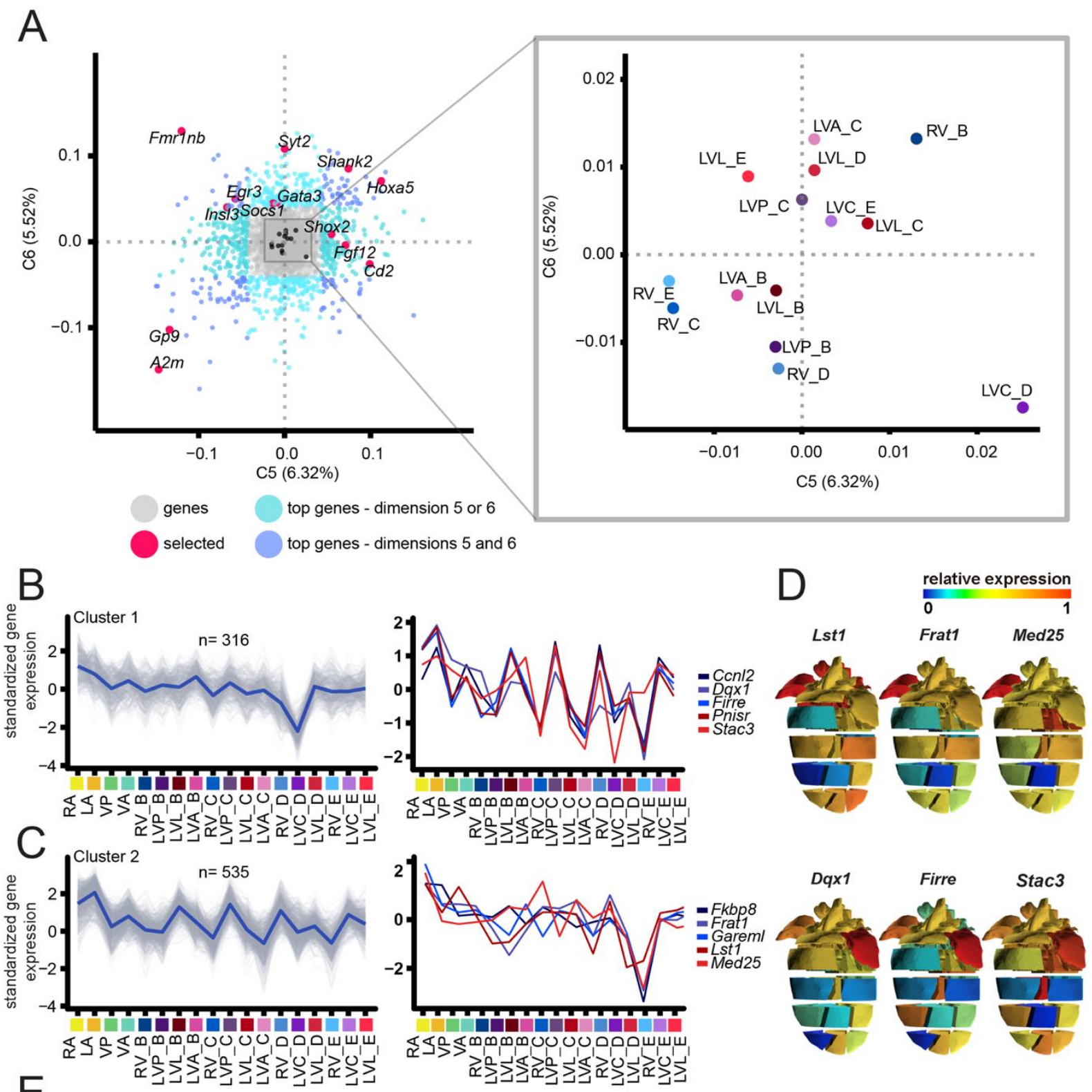

E
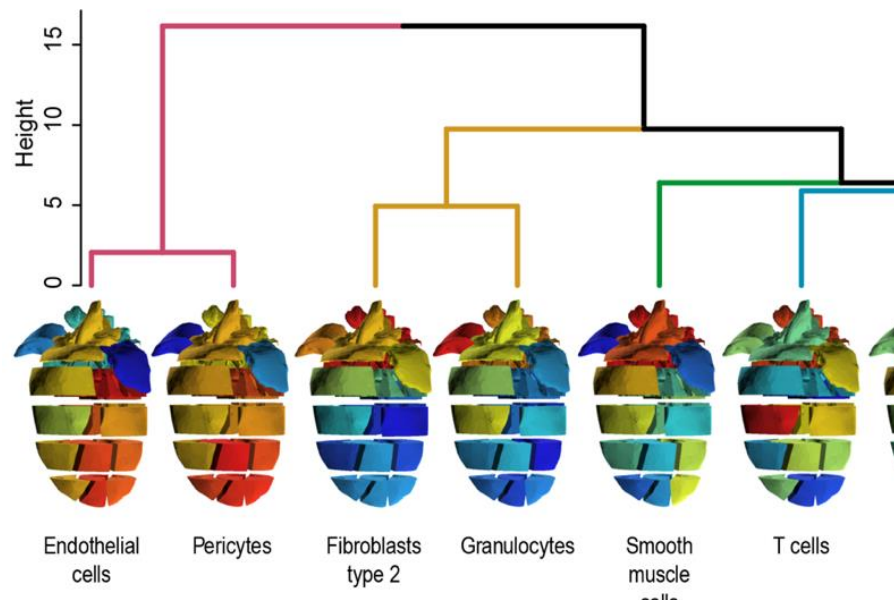

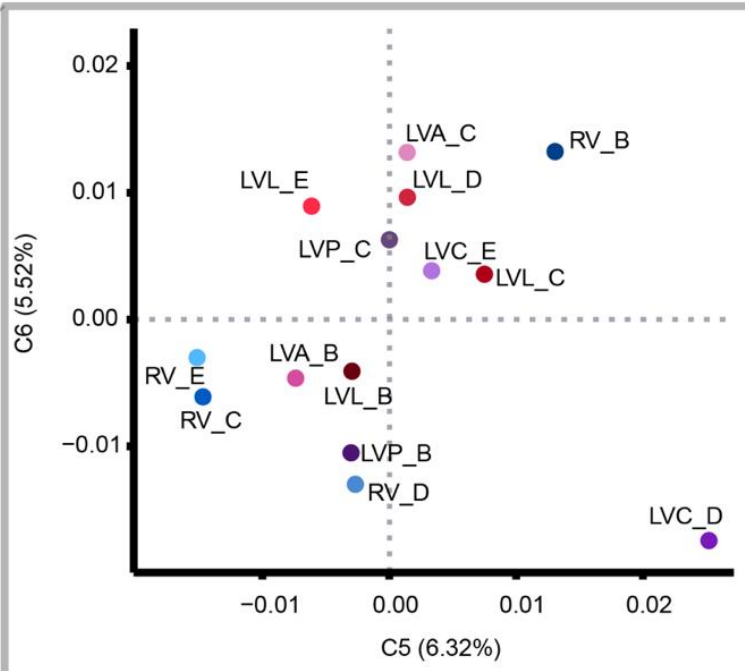


725 Figure 5: Further characterization of gene expression networks of the

726 ventricles

727 A) The biplot which shows the spread of the ventricular sections, and genes in components 5 and 6.

728 The biplot is enlarged at the coordinates of the ventricular sections to depict their spread. B-C)

729 Clusters identified which depict an atypical gene expression profile of the cardiac sections, and

730 individual gene expression profiles of selected genes within the identified clusters, which are also top

731 genes in A). D) Selected gene expression profiles in 3D respective to clusters $\mathrm{B}$ and C. E)

732 Hierarchical clustering of gene expression profiles of cell types across the heart.

733 


\section{Figure 6}
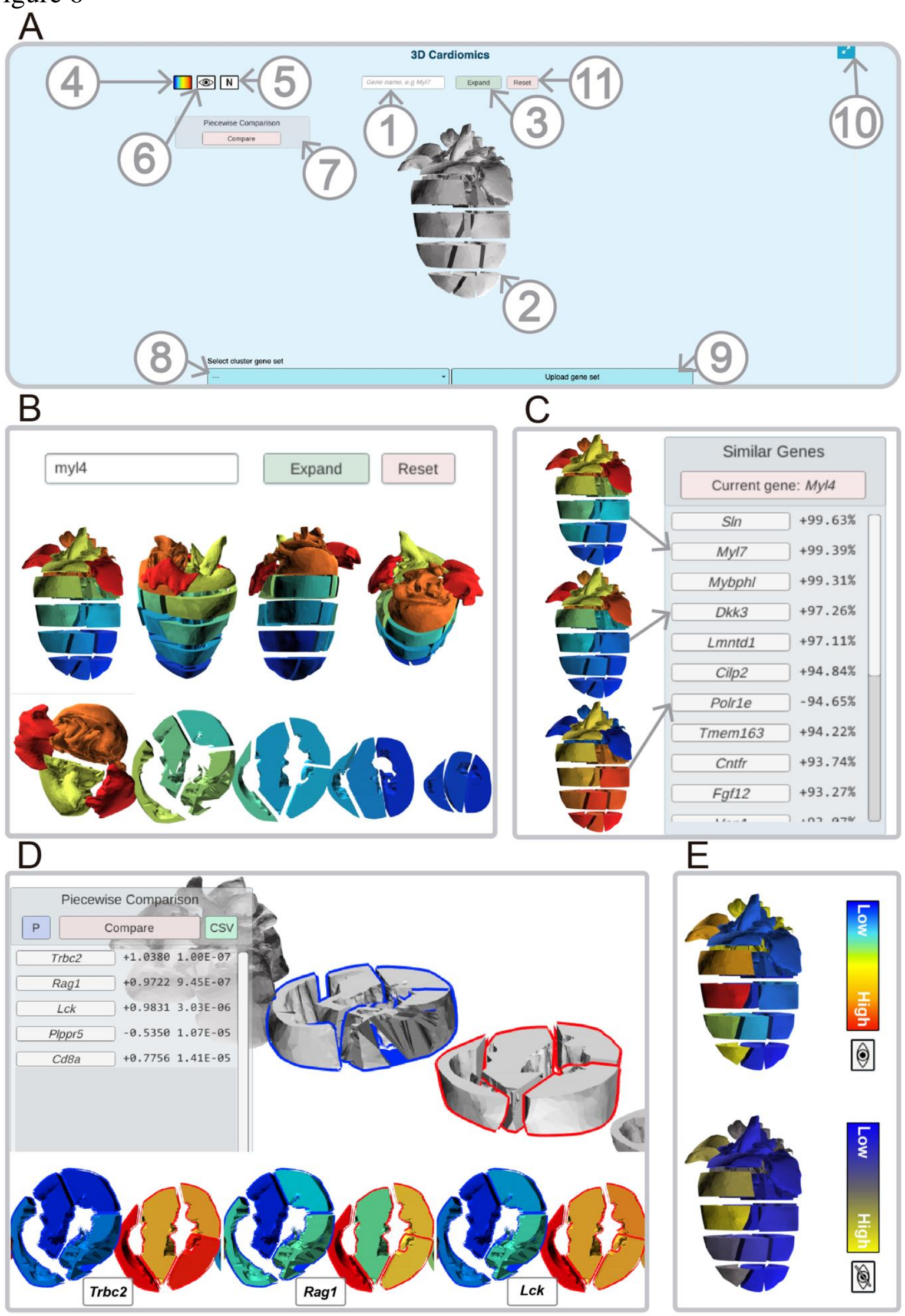
737 A) Guide to components of the interface; 1) Search tool for genes expressed in the heart, for visualization, 2) 3D heart model, which displays gene expression profile of selected genes, 3) expand/collapse button for the 3D heart. 4) Colour based scale of gene expression, 5) Button which enables relative expression, providing a gene score ranging from 0 to 1,6 ) color-blind color change option, 7) Cardiac section selector tool for pairwise differential gene expression, 8) Mean cluster (of this study) gene expression profile selection tool, 9) upload gene lists to obtain average signal across the heart, 10) enable full screen, and 11) reset analysis to collapsed heart, clear of gene expression. B)

744 Visualisation of a selected gene. Top row shows the gene entered into the search bar, middle row shows different angles of the 3D model with the expression pattern of Myl4, bottom row shows the expanded view of the 3D model. C) Comparison of genes with similar expression patterns. Once a gene is selected a window appears with a list of genes highly correlated with the gene that was visualized at the time, with their correlation percentages listed. D) Example of differential gene expression analysis between ventricular segments A and B. A list of DEGs would appear with their LFC values and FDR values. 'CSV' is an option of downloading the output. When genes are pressed the expression patterns can be visualized such as the examples shown. E) Visualization of expression patterns in the different colour formats. Top shows the default, and bottom shows the color-blind friendly option. 


\section{Supplementary Figure 1}

A
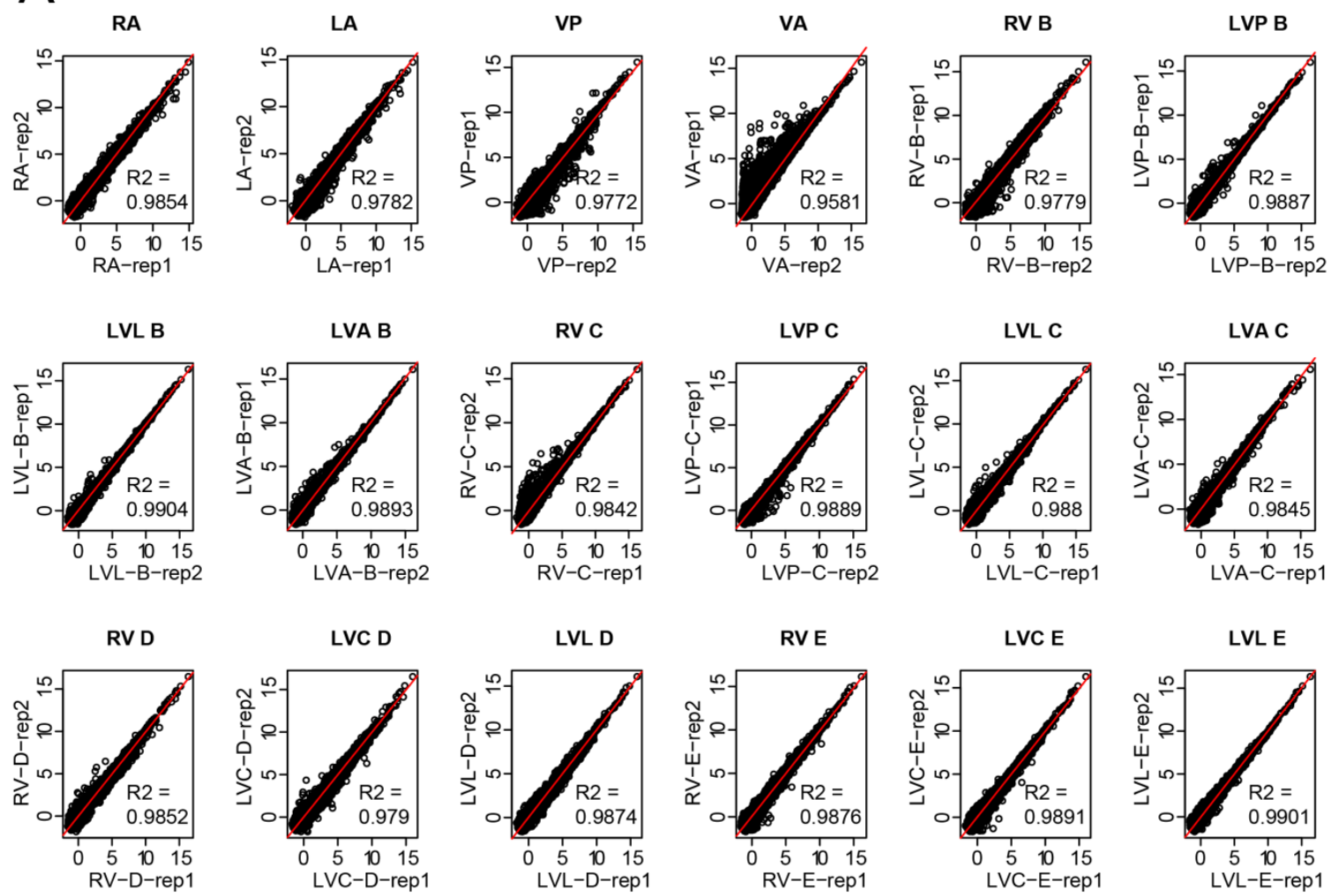

B

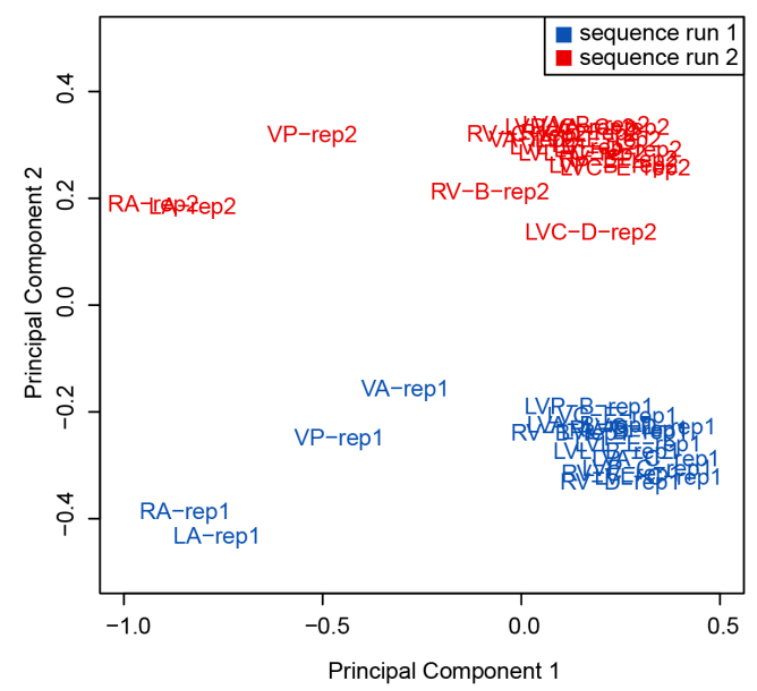

C

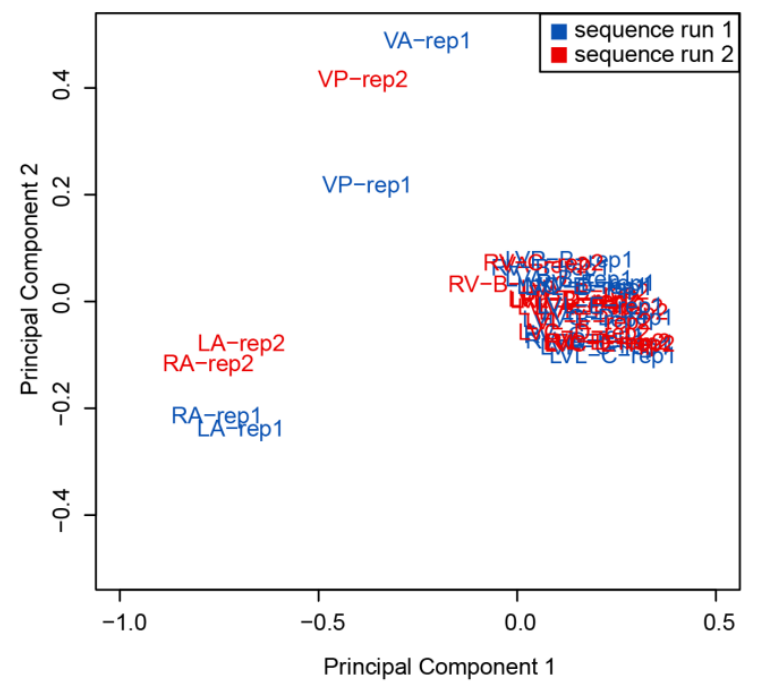


764 A) The correlation plots of counts of each gene for each of the replicates. B) Principal component

765 analysis of all samples before batch effect removal and C) after batch effect removal.

766

767

768

769

770

771

772

773

774

775

776

777

778

779

780

781

782

783

784

785

786

787 
Supplementary figure 2
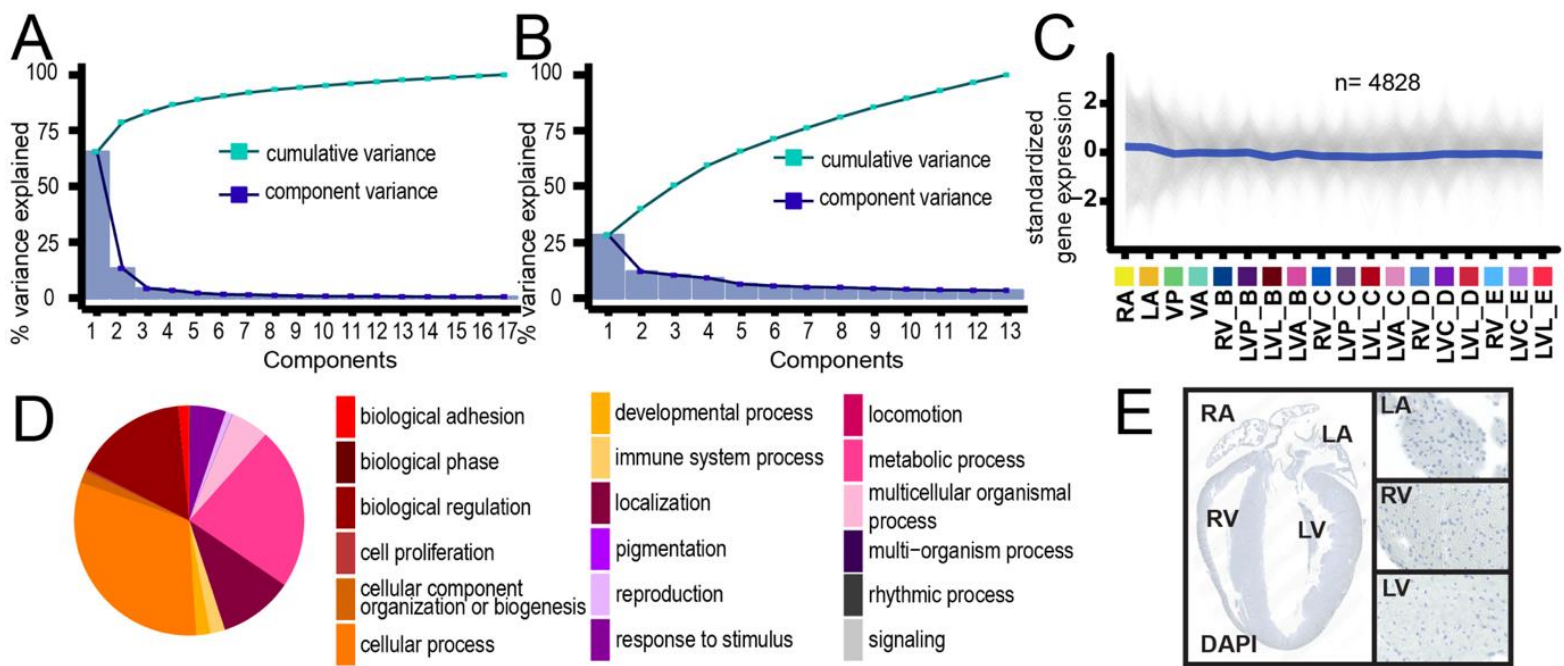

F
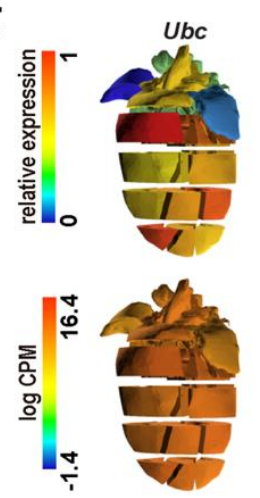

G
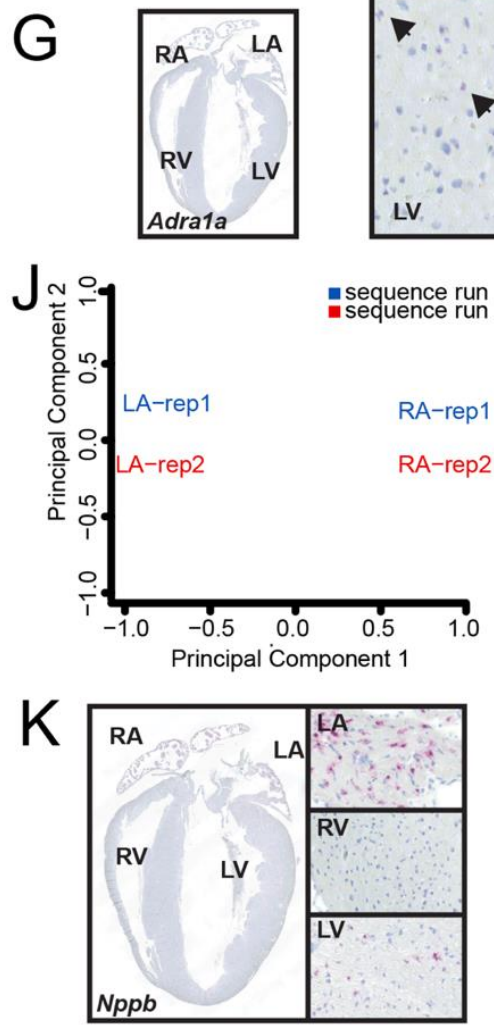
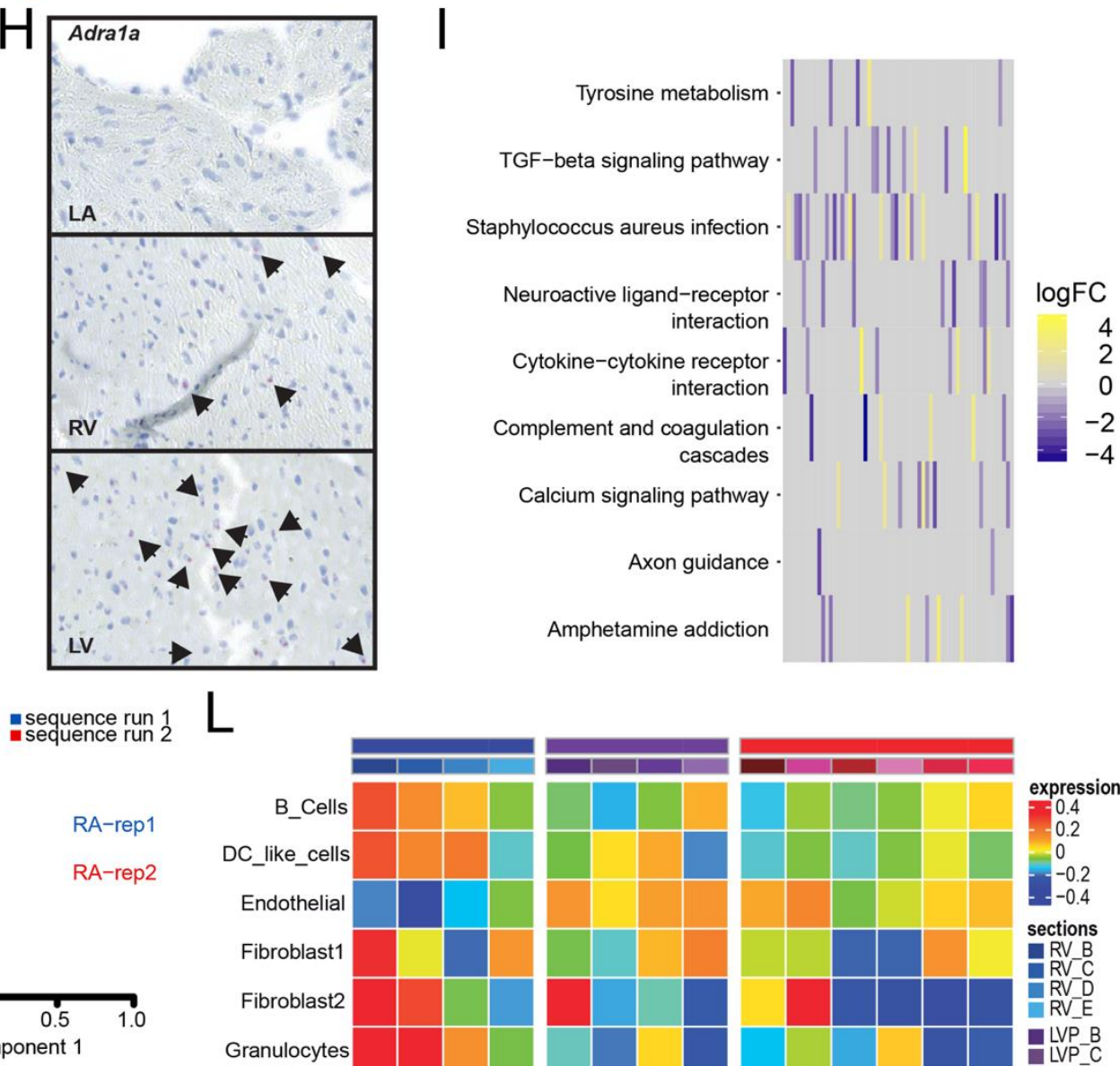

-0.2
-0

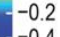

$-0.4$

sections

口R B B

RV_C

RVED

ranulocytes

Macrophages

Pericytes

Schwann_cells

Smooth_muscle

T_cells

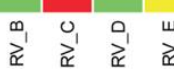


791 A-C) Variance explained by individual components, and cumulative variance across all components 792 of correspondence analysis with data of all sections in cpm A), and ventricular sections in cpm B). C)

793 All genes which had an alpha $<0.7$ in soft cluster analysis and D) the proportions of these genes in 794 enriched biological processes. E) RNA-scope DAPI control across main cardiac sections at 2.5X (left)

795 and 10X (right) magnification. F) Relative and log CPM expression of Ubc. Adrala expression at 796 2.5X magnification $\mathrm{G}$ ), and 10X magnification $\mathrm{H}$ ) across all cardiac sections. I) KEGG pathway 797 enrichment heatmap with differentially expressed genes between the left and right atria. J) PCA of 798 atrial sections and genes found in top enriched molecular functions of DGE analysis between the left 799 and right atria. K) RNA-scope of Nppb expression across main cardiac sections at 2.5X (left) and 10X 800 (right) magnification. L) Heatmap of average cell type expression across ventricular sections. 